TRABAJOS DE PREHISTORIA

68, N. ${ }^{\circ}$ 1, enero-junio 2011, pp. 123-146, ISSN: 0082-5638

doi: $10.3989 /$ tp.2011.11062

\title{
Práctica social, memoria y ritual en Cogotas I: esbozo teórico para un enfoque renovado
}

\author{
Social practice, memory and ritual in Cogotas I: theoretical outline for a renewed \\ approach
}

\author{
Antonio Blanco González (*)
}

\section{RESUMEN}

Este artículo se aproxima al ámbito ritual y simbólico de Cogotas I atendiendo a las prácticas sociales partícipes de su realidad material. Partiendo de algunos confusos tópicos historiográficos, se presenta un marco sociológico más relacional e inclusivo, inspirado en propuestas no positivistas. Se resalta la peculiar relación "histórica" e interactiva mantenida por tales comunidades con su pasado, así como la importancia de las actividades cotidianas ritualizadas en la reproducción de sus valores culturales. Se reivindica el ensayo de otros métodos de estudio del registro material de Cogotas I, cuya configuración y legibilidad responderían a tales pautas ordenadas y reiterativas. Como ejemplo, se revisan la reocupación de los campos de hoyos, el relleno de las fosas y la cerámica decorada con Boquique. Tales elementos ordinarios y cotidianos, inmersos en largas tradiciones culturales, revelan su cualidad de recursos mnemónicos, que presidieron la enculturación y socialización de los individuos.

\begin{abstract}
This paper examines the ritual and symbolic spheres of the Cogotas I Culture focusing on the social practices implicated in its material record. Taking some confusing historiographic themes as a starting point, a more relational and synoptic sociological framework is presented, inspired by non-positivist proposals. Highlighted is the particular "historical" and interactive relationship kept by such communities with their past, as well as the importance of the everyday ritualized activities in the reproduction of their cultural values. The paper requires a trial of new methods for studying the Cogotas I archaeo-
\end{abstract}

(*) Dpto. de Prehistoria, Historia Antigua y Arqueología Facultad de Geografía e Historia. C/ Cervantes s/n. 37002 Salamanca. Correo e.: ablancoglez@usal.es

Recibido: 8-V-2010; aceptado 2-VII-2010. logical record, whose formation and legibility would be the product of such structured and repetitive patterns. As an example, "pit sites" understood as palimpsests, the filling of the pits and the pottery with "Boquique" decoration are reexamined. Such ordinary and daily elements, embedded in long-term cultural traditions, are seen as mnemonic resources, with an important role in the enculturation of the social agents.

Palabras clave: Península Ibérica; Meseta; Edad del Bronce; Teoría; Historiografía.

Key words: Iberian Peninsula; Meseta; Bronze Age; Theory; Historiography.

\section{INTRODUCCIÓN}

En este artículo (1) se reflexiona sobre aspectos poco atendidos e infravalorados en el estudio de Cogotas I, principal grupo arqueológico de la Edad del Bronce del interior de la Península Ibérica. En concreto, se revisarán los argumentos sobre la dimensión simbólica y ritual de ciertos comportamientos no prácticos ni utilitarios, cuya racionalidad propia parece intervenir en la configuración de su registro material. El propósito último es identificar ciertas pautas significativas, atisbadas en la evidencia existente, y proponer enfoques que, a juicio del autor, permitirán construir una verdadera y rigurosa hipótesis de trabajo. Para ello se subrayarán las carencias más frecuentes de los planteamientos actuales al tratar

(1) Trabajo realizado en el marco del proyecto de investigación Nuevos hallazgos y nuevas perspectivas en el estudio de los restos humanos del grupo Cogotas I (HAR 2009-10105) del Ministerio de Ciencia e Innovación. 
sobre tales asuntos (2), y se insistirá en la idoneidad de adoptar un marco teórico alternativo.

El estudio de las sociedades de la Edad del Bronce en la Meseta - entre las cuales Cogotas I ocupa un gran protagonismo- ha progresado en la última década al socaire de nuevos objetivos que animan una agenda investigadora algo anquilosa$\mathrm{da}$, y unas evidencias consideradas ingratas e inexpresivas (Fernández-Posse 1998: 114). Se han emprendido ambiciosos programas de estudio desde las instituciones académicas y propuestas puntuales, pero muy oportunas, de renovación metodológica o conceptual. Se ha recurrido con asiduidad a la teoría sociológica desde fundamentos filosóficos afines materialistas, generalistas y deterministas, que comparten un predominante interés paleoeconómico y se centran en asuntos funcionales (Fernández-Posse 1998: 120-122; Díaz-del-Río 2001; Arnáiz y Montero 2003/04; Cruz Sánchez 2006/07; Celis Sánchez et al. 2007). Además el énfasis en los enfoques regionales a gran escala redunda en la caracterización de las regularidades, de procesos causalmente determinados y de las manifestaciones más infraestructurales de Cogotas I. Por contra, pocas veces se reflexiona sobre el orden ritual o simbólico de esta cultura, y ello a pesar de las perspectivas de estudio atisbadas desde tales aproximaciones (Valiente Maya 1993; González-Tablas y Fano Martínez 1994; Bellido Blanco 1996: 45-48; Delibes de Castro 2000/01; Enríquez y Drake 2007: 164-173). El cuadro resulta muy escorado: se ha intensificado la preocupación por el contexto -el territorio y el medioambiente-, la afinación temporal o una incipiente caracterización arqueométrica, pero otras cuestiones siguen sin ser planteadas.

El consenso en torno a tales directrices preside un panorama teórico y práctico que dificulta el avance en ciertas cuestiones básicas, frente a las cuales la investigación está desarmada: la aparente inexistencia de comportamientos funerarios normativos; la falta casi completa de auténticas cabañas; el ambiguo carácter -mundano o ritualde los campos de hoyos, etc. Para evitar una comprensión sesgada y parcial de Cogotas I, debiéramos estudiar otras manifestaciones de su realidad social, desplegadas a muy distinto nivel.

(2) El evento desencadenante de las reflexiones aquí vertidas por escrito, fue la reunión científica de Homenaje a $M .^{a} D o-$ lores Fernández-Posse. Cogotas I: una cultura de la Edad del Bronce en la Península Ibérica (Valladolid, 19-22 de octubre de 2009).
En suma, se propone un acercamiento más humanista, interpretativo y contextual a Cogotas I, que aportaría herramientas heurísticas y conceptos para una reflexión crítica. La imprescindible cautela que impone la ausencia de programas de investigación orientados desde tales planteamientos no invalida una lectura preliminar como la aquí esbozada. Reivindicamos la oportunidad de un cambio de enfoque, que procure nuevas lecturas al ampliar los campos de estudio o retomar los viejos asuntos bajo nueva luz. Nuestra hipótesis de partida asume que parte de las trazas materiales de Cogotas I no son meros restos inservibles, sino producto de actuaciones deliberadas, que siguen unas normas o esquemas de comportamiento compartidos y sancionados por los colectivos prehistóricos, es decir, que serían fruto de prácticas sociales.

\section{UN MARCO INTERPRETATIVO SINÓPTICO PARA COGOTAS I}

Tras el importante volumen de excavaciones arqueológicas acometidas, hoy día no puede invocarse ya lo aleatorio y poco representativo de nuestros conocimientos, ni la deficiente conservación del registro, para explicar algunos de los caracteres más controvertidos de Cogotas I. De hecho, se tiene constancia de comportamientos regulares, claramente pautados (Esparza 1990; Rodríguez Marcos y Abarquero 1997: 40; Díazdel-Río 2001), de amplia extensión en el espacio y muy dilatada prosecución en el tiempo. Por tanto, la ambivalencia e indefinición de los ámbitos funcionales domésticos (Castro Martínez et al. 1995: 67-68; Blasco Bosqued 2004: 572; Blasco Bosqued et al. 2007: 203-204) y funerarios (Esparza 1990; Blasco Bosqued et al. 1991; Castro Martínez et al. 1995: 71; Delibes de Castro 2000/01: 304) podrían interpretarse como rasgos definitorios o normativos de Cogotas I. El problema radicaría entonces en nuestra limitada comprensión de la naturaleza social de semejante registro material.

La reflexión previa nos lleva a tantear cuestiones eminentemente teóricas, basadas en postulados filosóficos, pues ante un problema teórico la solución ha de encontrarse en la propia teoría. Resultan muy esclarecedores ciertos trabajos, en la línea post/anti-procesual, de autores que al indagar sobre la inapropiada forma de pensar de 
los arqueólogos sobre la alteridad prehistórica (Shanks y Tilley 1987; Thomas 1996; Gamble 2001; Hernando Gonzalo 2002; Hodder y Hutson 2003; Bradley 2005) revisan críticamente tal problema, replanteándolo desde enfoques más acordes con los recientes desarrollos de la teoría social y antropológica.

El primer punto que se mencionará es la comprensión del ritual a través del registro arqueológico, según la distinción que establece Bradley (2005: 9) entre error y confusión. El estado de desconcierto de los planteamientos más usuales sobre Cogotas I al respecto entorpece nuestra aproximación al asunto. Distintos arqueólogos atribuyen tal confusión a la racionalidad implícita en nuestra mentalidad cartesiana, ilustrada o moderna-occidental, inapropiada para pensar sobre el pasado (Brück 2001: 314-318, 2006a). Esta actitud intelectual se funda en concepciones esencialistas, reduccionistas y dualistas, extrañas y no aplicables de manera transcultural en otras coordenadas espacio-temporales. La rica variabilidad social queda reducida a una lógica etnocéntrica y abstracta, formulada mediante categorías dicotómicas y apriorísticas (Shanks y Tilley 1987: 59; Thomas 1996: 12-17). La aplicación de tales esquemas partitivos a menudo ha comportado un análisis social descompuesto en instancias escindidas artificiosamente -la "economía", la "política", la "religión", etc.-, y concebidas como entidades autónomas. Se ha individualizado el ritual como esfera funcional segregada (3), que implica escenarios, practicantes y medios materiales distintivos, requiriendo conocimientos esotéricos y destrezas restringidas con propósitos no instrumentales. Así, en Cogotas I las "rutinas cotidianas" y las "actividades simbólicas" se contraponen como términos antagónicos y excluyentes (Blasco Bosqued et al. 2007: 45).

Falta unanimidad entre los pensadores sociales sobre el concepto de ritual, pero hoy día se concibe como un tipo de práctica social extendida entre los más diversos ámbitos: desde lo individual, arcano y consuetudinario a lo público, conspicuo y extraordinario. Se insiste en el concepto de "ritualización", como proceso dinámico de selección de ciertas prácticas sociales, a las que se provee de un especial énfasis (Bell 1992: 69-93).

(3) Tal como denunció Díaz-del-Río (2001: 157) sería el caso de la interpretación exclusivamente ritual, con propósito fúnebre, de los hoyos de Cogotas I (González-Tablas y Fano 1994).
Es además un fenómeno muy permeable en la mentalidad y los comportamientos no rituales, con gran capacidad de penetrar y tiznar de valores y significados la vida ordinaria de sus practicantes (Connerton 1989: 44-45). Ni el desempeño de las tareas cotidianas más neutras e insignificantes, ni aquellas manifestaciones más instrumentales y técnicas pueden considerarse ajenas a la ritualización (Ingold 1990; Dobres 2000; Bradley 2005; Brück 2006b: 307). Un elemento distintivo, aunque no invariable, del ritual es su puesta en escena mediante formalidades y convenciones muy estereotipadas y reiterativas (Bell 1992). Pero, en línea con un posicionamiento más global e inclusivo, tales actividades regladas no deben relacionarse sólo con aspectos religiosos -escatológicos o cosmogónicos-, sino también con meros propósitos prácticos, seglares o mundanos. Tampoco ha de asumirse que los mensajes transmitidos fueran descodificados y compartidos de forma unívoca por todos sus receptores, a pesar de los formalismos involucrados. En definitiva: los aspectos simbólicos y utilitarios, lo ritual y lo profano, sólo comparecen aislados desde el prisma analítico del investigador. Por tanto, ante la perspectiva de que el ritual se sirviera de los más prosaicos medios materiales de la vida doméstica y diaria en la Prehistoria Reciente, hoy se preconiza atender a la "ritualización" de las prácticas sociales así realzadas o acentuadas (Gosden y Lock 1998: 4; Hill 1995: 96-100; Bradley 2005: 33-35). La reinterpretación simbólica de los "basureros" y "fondos de cabaña" prehistóricos del mediodía peninsular es un buen ejemplo de aplicación de tales planteamientos (Márquez Romero 2002, 2004; Jiménez Jáimez y Márquez Romero 2008).

El segundo rasgo definitorio de la cultura de Cogotas I es su necesaria comprensión en un proceso histórico de largo alcance -el de la Prehistoria Reciente meseteña-, como estadio final de trayectorias convergentes y ciclos perpetuados a una escala milenaria (Delibes de Castro 2000/01). Además, como veremos, las comunidades de Cogotas I se hallan muy ligadas y restringidas, tanto física como mentalmente, a los usos y el mundo material tradicionales. En diversas ocasiones se ha planteado el tipo de reacciones posibles entre los grupos prehistóricos al encontrarse -incluso esporádica e involuntariamente-, con los restos materiales de sus predecesores (Bradley y Williams 1998; Gosden y Lock 1998; Bradley 
2002). Las huellas perdurables de los ancestros -reales o supuestos- requerirían ser comprendidas bajo la mentalidad prehistórica. Las actitudes adoptadas pudieron ser muy variadas (Bradley 2002: 13): desde ignorar tales testimonios, hasta emplearlos como pauta directriz en su comportamiento cultural. Su asimilación mediante relatos mitológicos y cosmogónicos, incluso cierta toma de conciencia sobre tal dimensión de su propia existencia, pudieron resultar factores de no poca enjundia. De hecho, se viene postulando que durante la Prehistoria Reciente el uso de la cultura material y su modificación pudieron emplearse para remarcar deliberada y explícitamente similitudes o contrastes con la tradición (Gosden y Lock 1998; Bradley 2002: 11-12). En la Península Ibérica algunos estudios sobre las reutilizaciones en monumentos megalíticos han comenzado a aplicar tal línea interpretativa (Beguiristán y Vélaz 1999; Lorrio y Montero Ruiz 2004; García Sanjuán 2005; Mataloto 2007). Asumiremos como presupuesto razonable que las huellas del pasado, muy presentes en el paisaje meseteño incluso hoy día, pudieron condicionar las prácticas sociales de las comunidades cogotenses, influyendo en diverso grado en sus preferencias culturales.

Frente a la capacidad individual de preservar y recuperar recuerdos, por "memoria social" entendemos la formulación colectiva de juicios convencionales sobre el pasado. Se trata de una táctica ideológica, propia de actitudes sociales activas y participativas hacia el mismo, muy diferente a la mentalidad moderna (Connerton 2009). La memoria como práctica intersubjetiva es un proceso selectivo que, a través de la interacción social, comporta olvidar ciertos episodios, seres, bienes o lugares para remarcar otros. Diversas versiones son debatidas y conciliadas en un argumento consensuado, cuya transmisión generacional queda garantizada (Hendon 2010: 10-12). Para estudiar la "memoria social" enfocaremos ciertas prácticas prescritas, repetitivas y persistentes de transferencia de esas representaciones convenidas del pasado (Connerton 1989: 6-40; McAnany y Hodder 2009: 10). Recientes estudios han profundizado sobre cómo el mundo material -que también incluye los testimonios pretéritos- configura el marco vital en que los grupos prehistóricos tejieron sus relaciones sociales e identitarias, a través de la memoria colectiva. Se ha comenzado a hablar de dispositivos mnemónicos, cuyo significa- do concreto no puede ser recuperado, pero cuyo funcionamiento viene siendo objeto de la Arqueología social en la última década (Van Dyke y Alcock 2003; Jones 2007; Mills y Walker 2008; Hendon 2010).

Entre los recursos y estrategias sociales dirigidos a inculcar y mantener el acervo cultural sobre el propio pasado, caben muy distintas manifestaciones materiales. El escrutinio del registro arqueológico desde tal perspectiva aconseja matizar dos grandes tipos de medios físicos evocativos. Connerton (1989) y Rowlands (1993) diferencian entre los dispositivos monumentales, conspicuos y públicos, y las prácticas cotidianas, vividas de forma implícita e inmediata. Entre los primeros las "ceremonias conmemorativas" hacen referencia explícita a eventos previos y prototípicos (Connerton 1989: 61-71). Mayor interés tiene aquí el segundo grupo de recursos, peor conocido ante la tradicional falta de interés que han despertado. Connerton (1989: 93-95) orienta gran parte de su estudio sobre ellos, insistiendo en el papel crucial de los "hábitos-memoria" (habit-memory) en la transmisión de conceptos sobre el pasado mediante "prácticas corporales" (bodily practices); habilidades automatizadas, repetitivas y formalizadas, que implican la interiorización de la memoria en un ámbito íntimo e involuntario.

Estas consideraciones comparten un marco intelectual muy desarrollado en la literatura arqueológica en las dos últimas décadas. Las teorías estructuracionistas (Barrett 1994: 36-37; Dobres y Robb 2000; Chapman 2000b; Hodder y Scott 2003: 90-105; Brück 2006a) han iluminado la cultura material desde conceptos sociológicos que tratan de superar viejos divorcios teóricos. Se atiende ahora al papel activo del mundo material, articulador de facetas sociales complementarias: las estructuras estables y predecibles y los individuos imprevisibles y cambiantes. Se reformula la relación entre las instituciones impersonales y duraderas y la capacidad de actuación contingente o social agency (Giddens 1995). Bourdieu (1972) lo ha expresado mediante el concepto de habitus: principios ordenadores de la conducta, que encauzan y suscitan el comportamiento humano, orquestando las prácticas sociales rutinarias, pero sin determinarlas. De hecho, el habitus se ayuda de los recursos materiales cotidianos para inculcar criterios, preferencias y normas de manera inconsciente o no discursiva, predisponiendo a actuar dentro de unas opciones concre- 
tas, cultural y socialmente sancionadas. Estos postulados teóricos, aplicados al registro arqueológico, han implementado enfoques sociales "de abajo hacia arriba" o de pequeña escala (Gamble 2001: 75-81). Reconsideran el papel social de los enseres ordinarios y de las costumbres más prosaicas, superando su lectura como meros receptáculos pasivos o inertes con información funcional o morfo-tipológica. Así, se han revalorizado las cualidades de la cultura material desde la interacción mutua entre objetos y sujetos: como medio estructurante de las actuaciones humanas, producto de ellas y al mismo tiempo marco físico y vivencial que las orienta y constriñe. Las prácticas sociales más comunes e "inocuas" y las artesanías más accesibles y extendidas (4), son campo abonado para la manipulación simbólica y política (Dobres y Hoffman 1994; Dietler y Herbich 1998; Dobres 2000: 108-117; Brück 2006b) y encierran por tanto un gran potencial interpretativo.

Los conceptos de "memoria social" y habitus enlazan con el último de los temas de este apartado: el de la tradición. Aquí trataremos las tradiciones culturales como estrategias sociales destinadas a manipular ideológicamente los procesos de enculturación y socialización. En cuanto principios instalados en el cuerpo social contribuyen eficazmente a instigar la sensación de invariabilidad y persistencia en el tiempo, a pesar de las transformaciones acaecidas (Hobsbawm 2002). En tal sentido Osborne (2008: 283-288) ha reflexionado sobre los conceptos de tradición y ritual a través del habitus, al conectar las actividades del tiempo presente con la actuación pretérita. Tal efecto se consigue mediante la recurrente participación en vivencias donde los conceptos culturales inmanentes se infiltran por todas las instancias sociales, a través de preceptos rituales y simbólicos, a menudo legitimados por su vinculación con la trayectoria precedente (Bell 1992: 118-142). Como señala Connerton (1989: 45), la ritualización se consigue mediante la repetición, y ésta promueve la perduración de actividades prototípicas (5). En suma, la invención, mantenimien-

(4) Even the most widely shared and ubiquitous of techniques are part and parcel of the body politic (Dobres 2000: 123).

(5) 'La 'tradición inventada' implica grupos de prácticas (...) de naturaleza simbólica o ritual, que buscan inculcar determinados valores o normas de comportamiento por medio de su repetición, lo cual implica automáticamente continuidad con el pasado" (Hobsbawm 2002: 8). to y sustitución de las usanzas y hábitos tradicionales es legible en el registro arqueológico al enfocar sobre las prácticas sociales repetitivas que lo generan. La apropiación o inhibición en el uso de fórmulas materiales tradicionales son opciones sociales deliberadas, dentro de estrategias ideológicas (Bradley 2002: 11).

En síntesis, hemos repasado una serie de conceptos sociales interrelacionados, desde planteamientos no dicotómicos, sino relacionales y holísticos, que nos permitirán atender a la simultaneidad, en unos tiempos y escenarios coincidentes, de lo cotidiano-mundano y lo simbólico-ritual, como facetas indisociables y ubicuas del mundo material en que se desenvolvieron las comunidades de Cogotas I. Se ha recalcado la importancia de orientarse hacia las prácticas sociales, y en especial, hacia aquellas formalizadas y sancionadas por la memoria social. Al proceder de este modo, destacaremos la dimensión inmediata y contingente del comportamiento, la de las vivencias y experiencias de los sujetos, iluminando aspectos mal conocidos de la cultura material de Cogotas I. A continuación ensayaremos tales conceptos acudiendo a ciertos provocativos textos en la línea contextual o interpretativa, tan a menudo ilustrados con vistosos "estudios de caso" cuidadosamente seleccionados. De su examen podría concluirse que el de Cogotas I bien pudiera ser uno de ellos.

\section{MEMORIA SOCIAL, TRADICIÓN Y HABITUS EN LA CULTURA MATERIAL DE COGOTAS I}

En esta sección se enfatizará la importancia del pasado en la sociedad de Cogotas I, así como el rastro físico que han dejado ciertas prácticas cotidianas, encauzadas mediante tradiciones de un inusitado componente ritual, y ligadas a actitudes afines al concepto de "memoria social". Nos centraremos en algunos de los elementos del registro material cogotense que según Fernández-Posse (1998: 241-243) más rendimiento científico pueden aportar a corto plazo: los campos de hoyos y sus fosas, junto con los sedimentos que las rellenan y los restos arqueológicos fragmentarios que contienen.

Una somera evaluación previa de Cogotas I nos lleva a recalar en la consistencia y regulari- 
dad alcanzada por sus expresiones culturales, caracterizadas por su fuerte conservadurismo (Harrison 1995: 71; Abarquero 1997: 829; Delibes de Castro 2000/01; Ruiz Zapatero 2007: 46-47). A la vista de la extensión, homogeneidad y tenacidad de los comportamientos que definen tal cultura, pudiéramos concluir, siguiendo a Fernández-Posse (1998: 115-116), que desde una lectura funcionalista alcanzó un indudable "éxito adaptativo". También es lícito afirmar que dicha adecuación óptima de sus modos de vida se perpetuó en sus aspectos más estructurales, absorbiendo los sucesivos e inevitables desajustes y atravesando, con el tiempo, unos umbrales demográficos, socio-políticos, productivos y ecológicos cambiantes. Lo distintivo del caso es que, a través de esas divergentes trayectorias históricas, la cultura material no experimentó cambios bruscos, mostrando las lentas variaciones puntuales una asombrosa uniformidad y resistencia. Buena parte de tal regularidad reproduce un acervo de prácticas vernáculas y arquetípicas, similares a las de sus antepasados (6), por lo que, al subrayarlas, Cogotas I pasa por ser una cultura muy atávica o conservadora. Esta peculiaridad justifica entender tales manifestaciones como tradiciones culturales (Hobsbawm 2002) y plantearnos cuál habrá sido el papel del pasado entre tales comunidades.

Un aspecto crítico de nuestro argumento es la conexión entre la específica apreciación del paso del tiempo por las gentes de Cogotas I y la adopción consciente de estrategias ideológicas y evocativas sobre el mismo. En sintonía con los actuales conocimientos antropológicos, y en ausencia de argumentos en contra, es lícito proponer que tales grupos prehistóricos percibían el tiempo como repetición episódica y cíclica de prácticas habituales y a su vez atávicas, que fluían entre los antepasados y su presente. La conciencia de una transformación acumulativa e irreversible pudo dotar a tales poblaciones de una específica dimensión "histórica" sobre su pasado (Esparza 2001; Hendon 2010: 14-26), frente a la mentalidad antihistórica, mitológica y circular o de "eterno retorno", sin consciencia del cambio, en la línea de M. Eliade y defendida por Kuna (1995). Los sujetos participantes de tal cultura pudieron

(6) Ya Esparza (1990: 137) advirtió que la diversidad funeraria de Cogotas I parece responder a "tradiciones ancestrales muy arraigadas". haber concebido el avatar pretérito como un estadio abierto e inacabado, que intervino activamente en su transcurrir consuetudinario (Gosden y Lock 1998; González Ruibal 2006/07: 107-109). Esa apreciación temporal, instalada en la mentalidad y la cosmovisión de las gentes de Cogotas I, requeriría de diversos medios para ser asimilada y perpetuada por los individuos (Connerton 1989; Bradley 2002). Al aplicar la mencionada distinción elemental entre recursos mnemónicos (Connerton 1989) al caso de Cogotas I, atisbamos que habrían funcionado varios tipos de estrategias. Entre las "ceremonias conmemorativas" encontramos ciertas prácticas inscritas en ciclos transculturales muy atávicos (Delibes de Castro 2000/01: 297-303), vigentes durante toda la Prehistoria Reciente y escenificadas en hitos paisajísticos extraordinarios: el arte rupestre esquemático, las ofrendas metálicas en santuarios, la reutilización de los recintos fosados, la frecuentación ritual de las cuevas o la intervención ¿votiva? en los monumentos tumulares del occidente meseteño (Delibes de Castro 2004). Sobre todo, nos interesa recalcar ahora las bodily practices; actividades ordinarias o consuetudinarias, gesticuladas de forma espontánea y compulsiva, que interiorizan "hábitos-memoria" como conocimiento "no discursivo" (Connerton 1989: 72-74). En este grupo encontraríamos las tareas más instrumentales y utilitarias, como sembrar los campos o participar en la elaboración, uso y amortización de los enseres y estructuras domésticas. Erigir una cabaña o excavar una fosa comportaron movilizar conocimientos prácticos muy formalizados y extendidos, como también desmantelar y hacer invisibles, de manera premeditada y concienzuda, tales rastros de intervención humana (Fernández-Posse 1998: 242-243).

En suma, en la comprensión de Cogotas I resulta revelador conjugar la probable intervención activa de ciertos elementos de su cultura material, y las destrezas que conllevó su manipulación, con la hipotética historicidad de su apreciación del tiempo. Sugerimos que en la transmisión de tales pautas de comportamiento -exitosas y funcionales- y en la comprensión de semejante concepción del cambio, pudo intervenir de manera decisiva la memoria social, aunando lo utilitario y lo simbólico, lo material y lo ideológico, lo funcional y lo ritual. Unas pautas tan formalizadas y reiteradas como las que examinaremos a continuación se explicarían mejor en tales términos. 


\subsection{Reocupación y palimpsestos de hoyos}

En el interior de la Península Ibérica la costumbre de cavar hoyos -polimorfos y multifuncionales-responde a unas prácticas sociales habituales y milenarias, documentadas ya entre los primeros grupos agrarios (Rojo et al. 2008). Las repetitivas y extendidas fosas de Cogotas I parecen constituir un recurso próximo, propio de la experiencia cotidiana; cualquier sujeto habría participado alguna vez en la vivencia de su excavación, uso o colmatado, conllevando costumbres muy extendidas y probablemente formalizadas.

Una primera característica crucial de los campos de hoyos es la intensidad de su reocupación diacrónica. Existe consenso en que responden a estancias recurrentes y discontinuas, en lugares a los que regresan las mismas $u$ otras gentes de forma reiterada e intermitente, generando un crecimiento horizontal, no pluriestratificado, de la evidencia (Fernández-Posse 1982: 149; Blasco Bosqued 2004: 571 y 577-578; Abarquero 2005: 42; Díaz-del-Río y Vicent 2006: 33-34). Tales notas se adecuan bien al concepto de palimpsesto (Díaz-del-Río 2001: 289), y más concretamente al de "palimpsesto acumulativo" de Bailey (2007: 204-205). Esta categoría se define por la pérdida de resolución funcional y temporal: las trazas de cada ocupación permanecen, pero difuminadas de tal forma que resulta muy difícil discernir patrones sincrónicos (Blasco Bosqued 2004: 577-578). El aspecto crítico estriba en comprender que su significado sobrepasa la suma de los episodios individuales constituyentes, tanto para los arqueólogos como, especialmente, para sus usuarios prehistóricos (Bailey 2007: 205). No se trata de un mero solapamiento o interferencia de depósitos "sin que medie la intención de establecer vínculos con los estratos infrayacentes" (McAnany y Hodder 2009: 9) pues, como puntualiza Mills (2009: 39), tal vinculación bien pudo entablarse a través de las experiencias humanas y en concreto, mediante técnicas mnemónicas. La presencia de las fosas en el paisaje ¿fue realmente preterida, olvidada para siempre? En algunos casos parece que el recuerdo de su misma ubicación perduró durante dilatados intervalos de tiempo. Tal hipótesis sería fácil de aceptar entre fases sucesivas dentro de Cogotas I, como ocurre en la Fábrica de Ladrillos (Blasco Bosqued et al. 2007) (Fig. 1) o en El Pelambre (González Fernández 2009). Pero incluso aquellos sitios domésticos

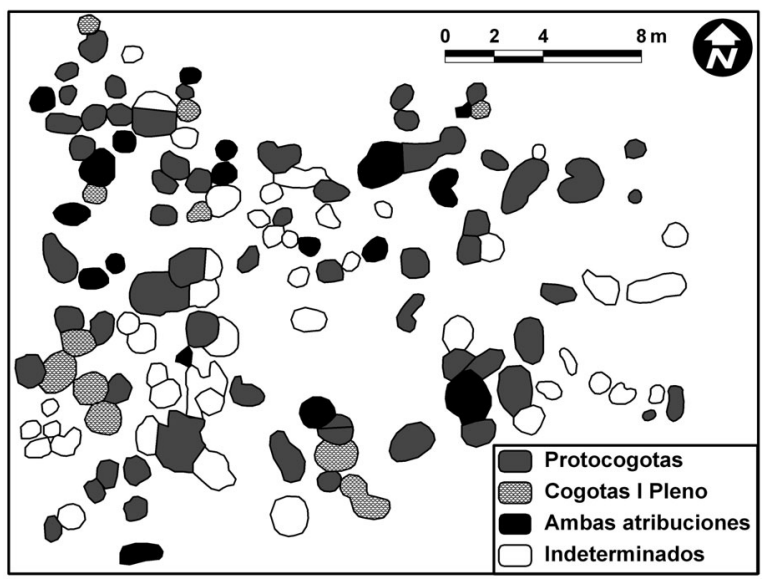

Fig. 1. Plano del campo de hoyos de la Fábrica de Ladrillos (Blasco Bosqued et al. 2007: 201, Fig. 113, redibujado) (localización en Fig. 3).

con ocupaciones separadas por intervalos pluriseculares (Díaz-del-Río 2001: 227-229) parecen mostrar una ordenación espacial intencionada, sólo comprensible de haber mediado "una continuidad funcional y de valores, tanto socioeconómicos como probablemente ideológicos" (Díaz-del-Río 2001: 229). Así pues, la recurrente coincidencia en el emplazamiento elegido no sólo se verifica entre fases próximas, sino muy a menudo entre ocupaciones remotas.

Para obtener una imagen mínimamente contrastada de este fenómeno, se exploraron los datos sobre yacimientos reconocidos en el territorio de Castilla y León, evaluando la reutilización por gentes de Cogotas I de emplazamientos con ocupaciones previas de la Prehistoria Reciente. Para ello se recopilaron los datos del Inventario Arqueológico de la administración autonómica, considerando sólo aquellas atribuciones seguras (Abarquero 2005: 76-83). El desglose detallado que se acompaña (Fig. 2) muestra que en el $36 \%$ de las estaciones con material atribuido al Bronce Medio (Protocogotas) se han reconocido ocupaciones previas (Fig. 2A), fenómeno que afecta al $50 \%$ de los sitios adscritos al Bronce Final (Cogotas I Pleno) (Fig. 2B). Destaca un mayor índice de reocupaciones múltiples -más de tres- en el dominio kárstico, especialmente en la provincia de Burgos, o vinculadas a recursos naturales -hídricos, agrarios, minerales-, siendo lo más usual la coincidencia de sólo dos fases. En segundo lugar, se han señalado asociaciones significativas entre los sitios Cogotas I y ocupaciones campaniformes y 
neolíticas, frente al patrón del Bronce Antiguo (Blasco Bosqued 2004: 571). Un simple recuento permite apreciar la continuidad entre el Bronce Medio y Final, pues coinciden en 66 ocasiones (Fig. 2B), mientras que Bronce Antiguo y Bronce Medio concurren en 47 casos (Fig. 2A). Respecto a la intensidad de la relación de las estaciones Cogotas I con fases anteriores de la Prehistoria Reciente, hemos cuantificado los casos seguros, con y sin ocupaciones previas, para las tres fases de la Edad del Bronce (Tab. 1A). Mediante la prueba de $\chi^{2}$ descartamos que las diferencias en dichas puntuaciones pudieran deberse a sesgos del muestreo o al puro azar (Tab. 1B). El resultado permite afir- mar que el patrón de reocupaciones/nuevas fundaciones en el Bronce Antiguo es estadísticamente diferente al operado en el Bronce Medio (BA versus $\mathrm{BM}$ ) y Bronce Final (BA versus $\mathrm{BF}$ ), pues en ambos supuestos cabe rechazar la hipótesis nula ( $p$ $<0,05)$, mientras que los valores del Bronce Medio y Final (BM versus $\mathrm{BF}$ ) resultan indistinguibles entre sí $(p=0,196)$, es decir, su diferencia no es significativa y forman parte de un comportamiento homogéneo.

A pesar de las severas limitaciones de la información manejada y el forzoso carácter preliminar del experimento, creemos que estos datos son representativos de una tendencia verificada cada
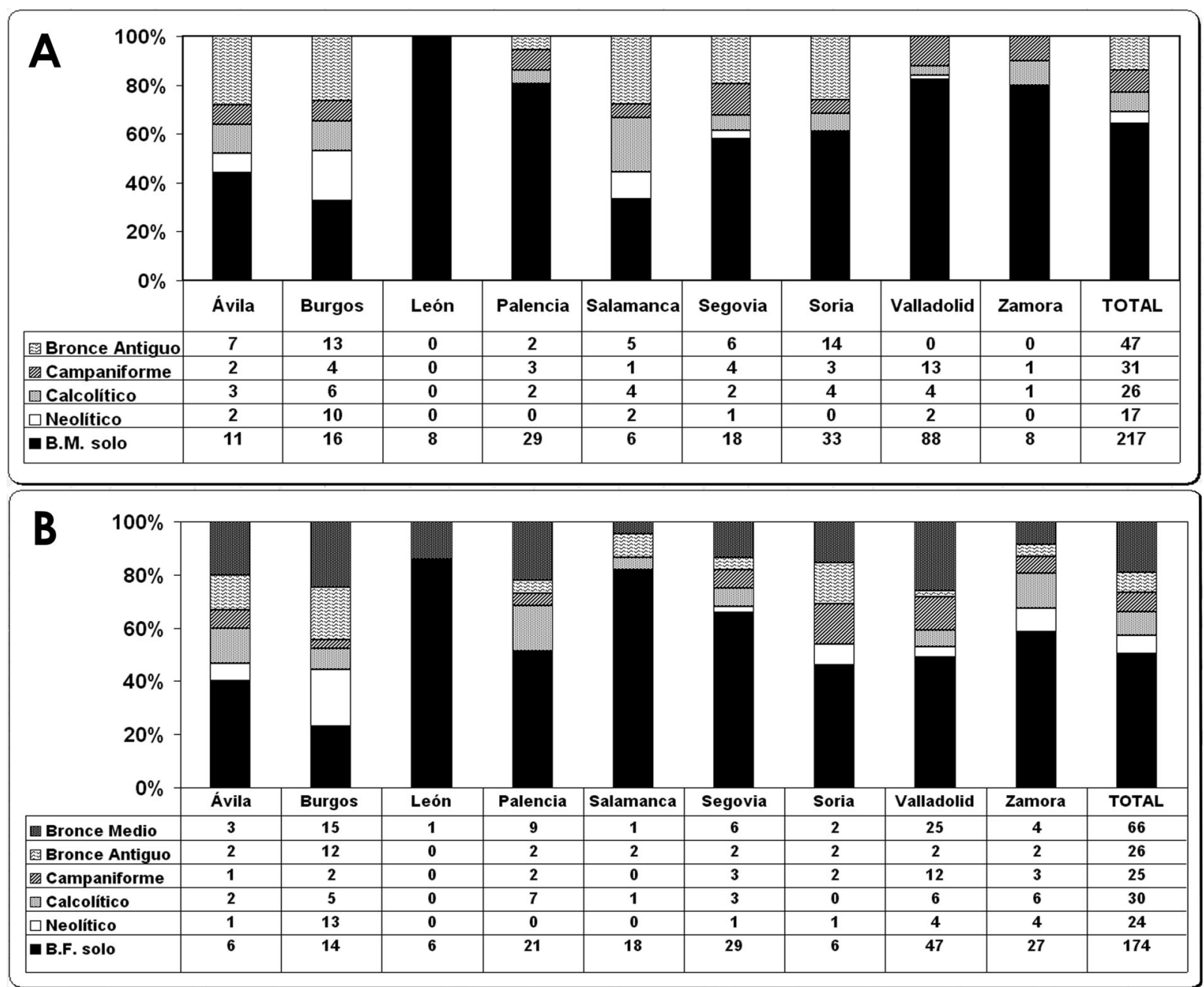

Fig. 2. Inventario Arqueológico de Castilla y León. Gráficos de barras acumulativas con datos por provincias de los sitios Cogotas I con y sin ocupaciones previas (a partir del Neolítico). A. Edad del Bronce Medio (B.M.). B. Edad del Bronce Final (B.F.).

T. P., 68, N. ${ }^{\circ}$ 1, enero-junio 2011, pp. 123-146, ISSN: 0082-5638 doi: $10.3989 /$ tp.2011.11062 


\begin{tabular}{|l|c|c|c|}
\hline \multicolumn{4}{|c|}{ A } \\
\hline & $\begin{array}{c}\text { Br. } \\
\text { Antiguo }\end{array}$ & $\begin{array}{c}\text { Br. } \\
\text { Medio }\end{array}$ & $\begin{array}{c}\text { Br. } \\
\text { Final }\end{array}$ \\
\hline Campaniforme & 46 & 31 & 25 \\
Calcolítico & 77 & 26 & 30 \\
Neolítico & 16 & 17 & 24 \\
Sin oc. previa & 260 & 217 & 174 \\
\hline \multicolumn{4}{|c|}{ B } \\
& $\begin{array}{c}\text { Chi } \\
\text { cuadrado }\end{array}$ & $\begin{array}{c}\text { Sig. } \\
\text { Asint. }\end{array}$ & $\begin{array}{c}\text { Valora- } \\
\text { ción }\end{array}$ \\
\hline BA vs BM & 15,55 &, 001 & d.s. \\
BA vs BF & 14,38 &, 002 & d.s. \\
BM vs BF & 4,69 &, 196 & d.n.s. \\
\hline
\end{tabular}

Tab. 1. Inventario Arqueológico de Castilla y León. A. Cómputo de sitios de las tres fases de la Edad del Bronce que tienen antecedentes prehistóricos o son ocupaciones ex novo. B. Test de $\chi^{2}(\mathrm{gl}=3 ; \alpha=0.05)$ cotejando entre sí los valores de la tabla $1 \mathrm{~A}$ para cada fase de la Edad del Bronce (d.s.= diferencia significativa; d.n.s.= diferencia no significativa).

vez con más frecuencia en las excavaciones arqueológicas en área abierta. El aspecto remarcable aquí es que los comportamientos que subyacen a tales patrones no quedan explicados de forma satisfactoria recurriendo sólo a motivaciones de orden funcional, económico o ambiental. Parece verosímil que los establecimientos de Cogotas I pudieran haberse visto también condicionados por factores locativos de atracción o repulsión, relacionados con ocupaciones previas de las que en gran parte no se conservaría recuerdo directo. En cierta medida las sedes domésticas ocupadas de forma reiterada durante la Prehistoria Reciente pudieron haber constituido memoriales de sociabilidad. En ellas se habría escenificado el encuentro cotidiano con trazas materiales vinculadas con su pasado (Hodder y Cessford 2004), enmarcando así la actualización rutinaria de la memoria social de tales grupos (7).

\subsection{Los hoyos y sus rellenos: ¿depósitos estructurados y estructurantes?}

En el estudio arqueológico de las fosas suele predominar el interés por la amplia gama de fun-

(7) The longer a site is inhabited, the more important local place becomes as a key element in the maintenance of cultural memory (Chapman 2000b: 4). ciones comprendidas en su uso primario (Martínez Navarrete 1988: 883-910; Bellido Blanco 1996: 21-56). Por contra, aquí proponemos reorientar los esfuerzos del análisis hacia su configuración secundaria y definitiva, de la que precisamente han quedado más y mejores testimonios. Este último aspecto a menudo se ha visto restringido a los esporádicos casos donde se identifican con certeza ciertos depósitos "especiales", indudablemente "intencionales" (Blasco Bosqued 2004: 572) por su contenido extraordinario (Bellido Blanco 1996: 45-48), como los de uso funerario (Esparza 1990; Blasco Bosqued et al. 1994) o las ofrendas faunísticas (Liesau et al. 2004/05; Liesau y Blasco Bosqued 2006), interpretados como fruto de secuencias gestuales complejas, dentro de tradiciones con claros precedentes locales. Sin embargo, la mayor parte del registro arqueológico que nos atañe comprende fenómenos mucho más sutiles. Su carácter distintivo sólo se deduce a partir de rasgos anómalos, que requieren métodos de estudio específicos e interpretaciones alternativas. En definitiva, no se requiere sólo ver, sino mirar; se trata, ante todo, de aprender a buscar.

La aproximación a tales peculiaridades del registro avanzaría sustancialmente, en primer término, mediante el replanteamiento crítico de ciertos presupuestos confusos, poco apropiados y muy extendidos. Suelen encontrase en la bibliografía arqueológica ciertas connotaciones peyorativas sobre las fosas entendidas como basureros (Hill 1995: 18-30); "simples colectores de desperdicios" o receptáculos higiénicos (Rodríguez Marcos y Abarquero 1997: 37 y 50; Castro Martínez et al. 1995: 68: Blasco Bosqued et al. 2007: 203; Enríquez y Drake 2007: 163-165). Con ello, los "rellenos" se interpretan como depósitos de formación no premeditada, en posición secundaria (Berggren 2009: 23-24). En consecuencia, los elementos materiales incluidos en las fosas serían residuos erráticos o detritus inadvertidos -restos de talla, cerámica fragmentada y fauna consumida, etc.-, incorporados a ellas de manera accidental y azarosa, desde las áreas domésticas próximas (Abarquero 1997: 82; Díaz-del-Río 2001; López Sáez y Blanco González 2004: 204). Frente a ello, diversas voces recuerdan que la basura no es una categoría universal, sino un concepto interpretativo, que depende de percepciones culturales (Hill 1995: 4; Esparza 2009: 187). Un pujante y heterogéneo horizonte teórico viene así a 
proponer métodos de estudio de los elementos interfaciales y sus rellenos desde otras coordenadas intelectuales. Cabría acudir al estudio de los procesos de formación del registro desde la arqueología conductual (Schiffer 1987), la deposición estructurada (Richards y Thomas 1984; Hill 1995: 95-96; Chapman 2000a, 2000b; Pollard 2001; Harding 2006) o la interpretación estratigráfica en términos sociales o social stratigraphy (McAnany y Hodder 2009). Además, vertidos higiénicos como los supuestos -discontinuos y sucesivos- generarían unos depósitos heterogéneos y estratificados. El que sean precisamente el tipo de relleno peor representado (Bellido Blanco 1996: 26; Arnáiz y Montero 2003/04: 105; Blasco Bosqued et al. 2007: 32) contradice abiertamente tal interpretación.

Tales planteamientos incitan a discutir cuestiones básicas, como la naturaleza y los procesos de formación del relleno -desatendidas, salvo alguna esporádica y valiosa reflexión (Díaz-delRío 2001: 118-123; Díaz-del-Río y Vicent 2006: 33)-, el registro exhaustivo y la cuantificación de sus contenidos o la caracterización sedimentológica de los vertidos (Blasco Bosqued et al. 2007: 377-380). Sin embargo, a pesar de las carencias de la documentación disponible, debe señalarse el antecedente de trabajos que contemplan los hoyos prehistóricos del interior peninsular desde otros presupuestos, eminentemente sociales y relacionados con el ceremonial (González-Tablas y Fano 1994: 100-102; Delibes de Castro 2000/01: 300-301; Arnáiz y Montero 2003/04: 105). Incluso se cuenta ya con experiencias recientes sobre trabajo de campo, que han tratado de contrastar hipótesis en esta línea (Enríquez y Drake 2007: 165-173; Rojo et al. 2008: 357-447).

En síntesis, estamos en condiciones de recopilar una serie de testimonios que reflejan la participación de prácticas rituales, de alto contenido simbólico, en el colmatado de los hoyos de Cogotas I. Refiriéndonos sólo a los últimos sitios publicados, Esparza (2009: 186-187) vislumbra pautas significativas en el contenido de los fondos de la Fábrica de Ladrillos (Blasco Bosqued et al. 2007): asociación de restos humanos y útiles óseos o broncíneos; disociación de restos de animales con restos humanos o molinos de granito; asociación de industria lítica y metales, etc. En el sitio pacense de El Carrascalejo también se apunta a patrones específicos, como la abundancia de cerámica decorada en el hoyo 17 , o mayor canti- dad de cerámica en el hoyo 30 frente al resto, o tres fosas sin ningún elemento (Enríquez y Drake 2007: 75-77 y 91). En El Pelambre (Villaornate, León), lo excepcional es el predominio de cerámicas finas y decoradas (González Fernández 2009: 283). Tales hechos obligan a reconocer cierta selección y orden en la disposición de los residuos, a pesar de su presunto carácter caótico. Tampoco su distribución dentro del hoyo es totalmente aleatoria, como muestra la Fábrica de Ladrillos, donde se ha reconocido que el material cerámico y lítico se concentra en el tercio superior del sedimento de las fosas (Blasco Bosqued et al. 2007: 41).

No menos significativa es la frecuente verificación en las estaciones de Cogotas I de un muy desigual estado de integridad de los recipientes cerámicos, siendo mucho más común encontrar sólo fragmentos inconexos (Enríquez y Drake 2007: 93). La rotura o el despiece intencionado, la selección de ciertos restos parciales -tanto de animales, como humanos o de cultura material $-\mathrm{y}$ su incorporación a los hoyos mediante gestos pautados forman parte de un comportamiento de carácter simbólico sobre el que se ha escrito bastante en los últimos años (Chapman 2000b: 49-104; Brück 2006a: 77-80; 2006b: 302-305). Se ha avanzado en los métodos para su identificación, pero sobre todo, se han esgrimido ideas para su comprensión social, como prácticas asociadas metafóricamente a la construcción de identidades relacionales (Chapman 2000b) y a procesos liminales -como muerte y regeneración-, o al tránsito entre estadios vitales. Tampoco resulta inusual entre Cogotas I el depósito de recipientes completos en posición invertida, como ocurre en el depósito de la "tumba 2" de la Fábrica de Ladrillos (Blasco Bosqued et al. 2007: 47-49, Fig. 18). Etnográficamente se trata de una pauta plagada de connotaciones simbólicas, como el exorcismo (Norman 2009). Por seguir con otros ejemplos, en el hoyo 41 de El Pelambre se incluyeron dos de los cinco únicos recipientes completos que deparó la excavación (González Fernández 2009: 133 y 284-285), ¿es puro azar? Un caso reseñable de fragmentación, por su íntimo vínculo con el pasado cercano, sería los restos humanos desmembrados o en posición secundaria, constatados con asiduidad entre los hoyos de Cogotas I (Esparza 1990; Díaz-del-Río 2001: 154-157 y 159; Blasco Bosqued et al. 2007: 63-64). Una vez más, el hecho suele plantear dudas sobre su ca- 
rácter selecto o desapercibido, siendo a menudo considerados tales restos como meros desechos (Blasco Bosqued et al. 2007: 45 y 64). Es más operativo asumir la hipótesis de su plena intencionalidad (González-Tablas y Fano 1994: 100) y rastrear la inserción de semejantes indicios -en absoluto esporádicos-, dentro de asociaciones significativas y reiterativas. Tal vez estos grupos participaran en costumbres de exposición y circulación de restos humanos, bien representados en otros contextos prehistóricos europeos (Chapman 2000b: 132-146; Brück 2006a: 80-85). Resulta tentador intuir la intervención física de los ancestros, en aquellas ocasiones en que su presencia fuera requerida en los asuntos de los vivos (Barrett 1994: 51) y, en esta línea, Connerton (1989: 68-69) reúne ejemplos etnográficos de rituales conmemorativos que escenifican la 'reaparición' de los ancestros.

Mucho más visibles son ciertos patrones reiterados que juegan con el binomio integridad/ruptura de macrorrestos líticos o faunísticos. Es frecuente la amortización de muelas de granito desgastadas, bien fragmentadas o completas, en fosas atribuidas a Protocogotas (Bellido 1996: 115), como los hoyos 100 y 56-57 de la Fábrica de Ladrillos (Blasco Bosqued et al. 2007: 44-47) o el hoyo 17 de El Carrascalejo (Enríquez y Drake 2007: 75-77). Se alegan motivos funcionales para explicar tal gesto, en relación con el abandono del lugar, como facilitar una pronta localización y un sencillo acceso aplazado a tan pesados materiales al regreso (Blasco Bosqued et al. 2007: 45). En cambio, siguiendo a Brück (2006b: 303), podría interpretarse como un símbolo de transformación, de cambio de estado, y de conclusión de un tipo de relaciones sociales y su reemplazo por otras nuevas. Respecto al despiece de fauna, también asociada a hoyos Protocogotas, recientes estudios (Liesau et al. 2004/05; Liesau y Blasco Bosqued 2006) reconocen el depósito de porciones apendiculares y axiales de terneras, las de mayor masa cárnica, así como cuartos delanteros, traseros y del esqueleto axial, interpretados -ante la ausencia de marcas de descarnado- como ofrendas votivas, de las que sus oferentes hubieron de privarse.

En último lugar, conviene reivindicar una reflexión sobre el significado de la estratigrafía de los hoyos en términos sociales (McAnany y Hodder 2009). La perspectiva tradicional, orientada hacia los objetos, contempla la matriz sedimentaria como un marco neutro y aséptico don- de hallar piezas de interés. Aquí se defiende el estudio de los depósitos sedimentarios de origen antrópico, no como meros continentes o "canteras" de objetos, sino como unidades significativas en sí mismas, parte intrínseca del registro arqueológico (Martínez Navarrete 1988). Ha de revalorizarse el estudio de los propios sedimentos de los hoyos -el elemento más olvidadocomo contenidos y no sólo como contenedores (Berggren 2009: 23-24). Debemos reconsiderar su específico proceso de vertido y el efecto conseguido: un resultado deliberado -sólo parcialmente azaroso- que comportó sedimentos y materiales muy probablemente seleccionados, empleados siempre para el colmatado sistemático y total de las fosas (Fernández-Posse 1998: 241-242). Estamos, en definitiva, ante aportes muy alejados del concepto de "conjunto cerrado" que erróneamente se les aplica en ocasiones. Por ello, no debe extrañar que al datar por radiocarbono muestras de vida corta de una misma fosa, se aprecie que "se colmató con restos de al menos dos momentos" (Abarquero y Delibes de Castro et al. 2009: 206), algo que ya se había constatado en hoyos neolíticos (Rojo et al. 2008: 223-225). Como se ha insinuado (Thomas 1999: 87; Brück 2006b: 303), pudieron recogerse materiales previos -sedimentos, fragmentos cerámicos y óseos, etc.- que harían referencia a antiguos estadios de ocupación del sitio, como reminiscencias de su pasado. Sería el caso de las cerámicas neolíticas incorporadas "dentro de los mismos hoyos" que otros materiales Protocogotas en La Horra (Palomino et al. 1999: 29).

En suma, los testimonios compilados -aún esporádicos, pero significativos- permiten intuir que en la conformación de los hoyos de Cogotas I intervinieron prácticas sociales muy pautadas y reiteradas, no atribuibles sólo a cuestiones instrumentales. Además, lejos de tratarse de un comportamiento exclusivo de Cogotas I, se verifican esquemas similares entre los grupos agrarios previos. Serían fruto de actividades cotidianas, utilitarias y a su vez ceremoniales, que en ocasiones reprodujeron una suerte de "estética de la deposición" (Pollard 2001: 315-318; Rojo et al. 2008: 357-378), y que perpetúan comportamientos de una larga trayectoria. Esta filosofía es la que ha presidido el estudio del campo de hoyos Protocogotas de Carrascalejo (Badajoz). Allí la amortización homogénea -verificada mediante estudios sedimentológicos-, relativamente rápida e inten- 
cional de las fosas, se explica como fruto de unos gestos festivos y ceremoniales, relacionados con la clausura y abandono del lugar agrario (Enríquez y Drake 2007: 170-171). Tampoco habría que descartar un ritmo paulatino y cotidiano de tales prácticas de amortización (Harding 2006: 121-124), tal vez relacionadas con eventos sociales cíclicos, de la trayectoria del poblado o de la biografía de sus habitantes (Thomas 1999: 70-71; Brück 2006b: 298-299).

Una parte de los hoyos parece responder a tales actuaciones episódicas y arquetípicas, de profunda raigambre temporal, que fijarían ciertos eventos sociales -como los ritos de tránsito- en el tiempo y el espacio (Brück 2006b: 298-299), insertándolos a su vez en recurrentes "paisajes de la memoria" (Thomas 1999: 70). El ritual aparece como "algo sedimentado y con fuertes raíces en la tradición (...) a través de una liturgia plagada de arcaísmos" (Delibes de Castro 2000/01: 297). Tales gestos rutinarios, compartirían ese énfasis especial (Bell 1992; Bradley 2002) que permite identificar acciones ritualizadas de vertido, y para cuya mejor definición se ha apuntado la oportunidad de recurrir a la estadística multivariante (Esparza 2009: 186-187). Remedando el título de este epígrafe, hemos reunido algunos indicios sobre hoyos que pudieron constituir depósitos estructurados (Richards y Thomas 1984; Chapman 2000b); fruto de gestos pautados y repetitivos, "ritualizados". Además de servir a la solución de asuntos utilitarios, en su formación habrían intervenido gestos que responden a otra lógica. En este último sentido, unas costumbres tan rutinarias habrían contribuido al complejo proceso de enculturación del individuo, mediante la afirmación e interiorización de habitus (Bourdieu 1972). Por eso también pueden considerarse medios estructurantes (Giddens 1995), recursos materiales a través de los cuales se cuestionaron y reprodujeron las estructuras sociales.

\subsection{La alfarería de Cogotas I}

El estilo alfarero de Cogotas I se caracteriza por patrones decorativos geométricos y no figurativos, profusamente representados y de sorprendente amplitud geográfica y perduración temporal (Fernández-Posse 1982; 1986/87; Abarquero 1997; 2005; Ruiz Zapatero 2007: 46-47). Disponemos de escasas lecturas interpretativas sobre el engranaje de tal alfarería en los muy diversos entramados socio-económicos en que se insertó. Ninguna de ellas se ha enfocado desde las regiones consideradas "nucleares" u oriundas, y los argumentos funcionalistas esgrimidos no consiguen explicar de forma satisfactoria ni su proyección geográfica, ni su persistencia plurisecular. Harrison (1995: 74) propone interpretar tal manifestación cultural como una vajilla al servicio de banquetes ceremoniales y comunitarios, para el consumo de alimentos sólidos. Hasta ahora, la ausencia de estudios específicos sobre residuos (Blasco Bosqued et al. 2007: 206) impide verificar tal hipótesis. Abarquero (1997: 82-87) por su parte, defiende su carácter doméstico, de autoabastecimiento, como una producción no elitista, desprovista de carácter sacro o ritual, cuya intención decorativa sería meramente estética, del "arte por el arte". Su difusión peninsular se relaciona con prácticas sociales, esencialmente exogámicas, para las que se alega una alta demanda por su pintoresquismo y novedad, que colmaría una necesidad transcultural de disponer de tales servicios entre grupos sin producciones análogas (Abarquero 1997: 90-93, 2005: 448-452).

Aquí exprimiremos algunos rasgos intrínsecos de la cerámica de Cogotas I, centrándonos en aquellos que informan de su peculiar genealogía y, sobre todo, del ámbito social de su manufactura y los conocimientos "no discursivos" que conllevaría. Con ello se pretende reconsiderar el rol de su dimensión simbólica, enfatizando la ritualización de los contextos en que tales artesanías cobrarían un mayor significado.

\subsubsection{Genealogía del estilo Cogotas I: la invención de una tradición}

Comenzaremos el epígrafe rastreando la inspiración temática de la ornamentación de Cogotas I. Es el tema clásico de su filiación o genealogía (Castro Martínez et al. 1995: 51-60; Fernández-Posse 1998: 11-24; Abarquero 2005: 24-26), que aquí abordaremos desde otros planteamientos y con renovadas expectativas. La génesis autóctona del Boquique y la incisión, y su hondo rastreo en los antecedentes prehistóricos, es una idea que, si bien se menciona esporádicamente desde los años 1920, fue sistematizada por Maluquer de Motes (1956: 196) al formular su tesis de la dualidad de tradiciones indígenas y 
hallstátticas. Como señaló Fernández-Posse (1982: 147), en el esquema dualista de Maluquer de Motes (1954), el indigenismo de Cogotas I se sustentaba exclusivamente en la afinidad formal de su decoración incisa respecto a la campaniforme. Desde finales de los años 1970 diversos autores, de forma simultánea (Molina y Arteaga 1976: 176-190; Fernández-Posse 1981: 75-76 y 78) se replantearon tales similitudes, extendiendo el autoctonismo a toda la alfarería. A ello contribuyó la flexibilización del marco interpretativo étnico-cultural e invasionista, y el derrumbe de las bases cronológicas de la ortodoxia instalada por Maluquer de Motes (1956). Fernández-Posse (1982: 139-149, 1986/87: 477) enunció el estado de la cuestión en su versión definitiva, y desde entonces, la vinculación del estilo Cogotas I con producciones alfareras locales y precedentes -neolíticas y del campaniforme Ciempozuelosse ha consolidado como hipótesis consensuada, si bien los términos en que se planteó no han vuelto a ser objeto de revisión ni debate. Aquí queremos insistir en que la propuesta de esta autora (Fernández-Posse 1982: 148-149) subraya el carácter orgánico o integral del arraigo en el sustrato cultural autóctono de todas las técnicas decorativas de Cogotas I. Aquella intuición, tildada entonces por ella misma como una "mera suposición", adolecía de la ausencia de "nexos materiales intermedios" (Fernández-Posse 1982: 149). Hoy, a la luz de la información disponible, y considerando el problema bajo otros prismas, conviene replantear esa inspiración en los repertorios locales precedentes como fenómeno no sólo verificado, sino de una "profundidad temporal" inusitada.

El vínculo con el fenómeno campaniforme requiere un enfoque alternativo. El radiocarbono va acortando la distancia entre los últimos Ciempozuelos y Protocogotas. Si bien por ahora no disponemos de fechas más antiguas de $c a .1800 \mathrm{cal}$ AC para Protocogotas, ciertas dataciones del campaniforme frisan e incluso alcanzan puntualmente el II milenio cal AC (Garrido Pena 2000: 195-196). Una serie de horizontes de comienzos de la Edad del Bronce llenarían ese aparente vacío: los conjuntos de cerámicas lisas del Bronce Pleno o "Clásico" madrileño (Blasco Bosqued 2004: 557-560) y el grupo Parpantique duriense (Jimeno 1988). Por tanto nos hallamos ante una dudosa discontinuidad cronológica y artesanal para la transmisión de tal decoración alfarera. Sin embargo, una estricta ilación temporal no es ne- cesaria para comprender semejante fenómeno, si atendemos a la muy probable sincronía, a fines del III milenio AC, de tales grupos arqueológicos y los últimos repertorios campaniformes (Díaz-del-Río 2001: 69-71; Rodríguez Marcos 2008: 409-410). El nexo con formas tradicionales se comprendería mejor en un marco creativo, menos rígido y unilineal, de hibridación de expresiones culturales (Jimeno 1988: 112-116; Fernández Moreno y Jimeno 1992: 224-225; Samaniego et al. 2001: 99-100) y revalorando la aportación de los grupos del Bronce Antiguo al repertorio alfarero cogotense (Rodríguez Marcos 2008: 320). En dicho escenario tendría buena cabida la transferencia o la imitación deliberada de antiguos ornatos alfareros. Se comprendería así mejor la coexistencia, en el oriente meseteño, del campaniforme y los primeros vasos Protocogotas en el nivel II de la cueva de Arevalillo de Cega (Fernández-Posse 1981: 81), o la (re)introducción de la temática incisa geométrica en momentos avanzados del Bronce Antiguo (2200-1900 cal AC) en Cueva Maja (Samaniego et al. 2001: 73-76). Por consiguiente, los primeros testimonios alfareros Protocogotas plantean esas influencias múltiples, tanto coetáneas como pretéritas. Por una parte prolongan la alfarería "de basto" o de cocina/almacenaje típica del Bronce Antiguo. Por otra se caracterizan por la adopción sincrética de motivos incisos muy arraigados, con un probable acento ritual. Estos proceden de la tradición calcolítica previa -triángulos, puntillados, etc. (Samaniego et al. 2001: 100)-, y también se inspiran en el campaniforme -composiciones radiales, en friso y metopadas, al interior del borde y con pasta blanca- pues precisamente motivos del estilo Ciempozuelos como la "espiguilla", los reticulados y las cenefas con puntos al tresbolillo, se encuentran entre los más extendidos en la Submeseta Norte (Garrido Pena 2000: 119-120, Fig. 48, temas 9,6 y 12).

En segundo lugar, en el caso del Boquique, queda por explicar cómo fue posible el referido abolengo neolítico apuntado por Fernández-Posse (1982: 139-141), al haberse agrandado sustancialmente la brecha en tal relación. La autora, tras descartar otras posibilidades, señalaba al Boquique del Neolítico Interior medio-tardío como claro precedente del cogotense (Fernández-Posse 1982: 147-149). Hoy sabemos que tal técnica alfarera comparece en contextos del Neolítico antiguo del último tercio del VI milenio cal AC, 
siendo coetánea por tanto del horizonte cardial mediterráneo, y propia -aunque no exclusiva- del interior peninsular (Alday et al. 2008: 164-165; Alday 2009: 135-137). Con posterioridad su empleo en la Meseta se rarifica durante milenios -no así en el nordeste peninsular, donde acusa cierto predicamento en el Bronce Antiguo (Maya y Petit 1986)-, si bien algún testimonio del III milenio AC resulta muy esclarecedor. En efecto, los trazos de los cérvidos al interior del cuenco madrileño de Las Carolinas se delinearon con Boquique (Blasco Bosqued y Baena 1996: 431, Lám. II), mostrando su uso restrictivo, de alto valor simbólico, entre la vajilla campaniforme Ciempozuelos. Tal técnica pudo pues pasar a ser empleada de forma puntual, para revestir de una aureola arcaizante a ciertos productos alfareros exclusivos.

Por último, la génesis de la técnica excisa en Cogotas I hoy no puede explicarse convincentemente de forma unívoca (Rodríguez Marcos 2008: 372). Esta técnica podría haberse inspirado tanto en los precedentes locales impresos o "pseudoexcisos" de Ciempozuelos (Molina y Arteaga 1976: 176-190; Fernández-Posse 1982: 145-147), como resultar de la interacción con otras alfarerías (8) del Bronce Medio, cuando en gran parte se desarrolla Cogotas I (Abarquero y Delibes de Castro 2009: 207-208).

En el cuadro que acaba de presentarse, la reocupación de los mismos enclaves en el sentido apuntado por Fernández-Posse (1982: 149) facilitó el contacto de los alfareros de la Edad del Bronce con los restos "arqueológicos" de sus antecesores neolíticos y calcolíticos (9). La "pervivencia de elementos residuales", cuestionada por Díaz-del-Río (2001: 322), no sólo habría sido posible en el pasado, sino que pudo formar parte de estrategias culturales intencionales. Por tanto, resulta ineludible plantear el encuentro cotidiano -en cuevas, megalitos o campos de hoyos- con cerámicas neolíticas, siendo un requisito material que posibilitó la emulación y reintroducción de viejas técnicas, como el Boquique. Muy distinto sería explicar la decisión cultural de remedar ta-

(8) En cuyo caso se trataría de "imitaciones de algo que se ha visto, sin dominar el procedimiento" (Blasco Bosqued y Lucas Pellicer 2001: 224-225, nota 1), probablemente a partir de prototipos transpirenaicos (Delibes de Castro et al. 2000; Rodríguez Marcos 2008: 371-372).

(9) Piénsese en los campos de hoyos, donde-salvo en el interior de las fosas- los débiles procesos de sedimentación favorecen la dispersión de los restos, proceso agravado en el sustrato arenoso y suelto de las campiñas meseteñas. les alfarerías (Dobres 2000; Brück 2006b: 307). Una representación a escala peninsular (Fig. 3) de los hallazgos de Boquiques neolíticos (Alday 2009) y del "área nuclear" y la "zona de contacto" de Cogotas I (Abarquero 2005) muestra que ambos fenómenos coinciden parcialmente y que la distribución del Boquique excede el ámbito cultural de Cogotas I. Es decir, su reproducción durante la Edad del Bronce -presuntamente inspirada en los precedentes neolíticos- habría respondido en última instancia a una lógica cultural selectiva, exclusiva de ciertas regiones y momentos del interior peninsular (Rodríguez Marcos 2008: 364-366), frente a otros contextos donde no fraguó, como el estuario del Tajo o la cuenca media del Guadiana.

En suma, la genealogía de las técnicas decorativas de Cogotas I podría entenderse por la mediación de tradiciones tecnológicas de larga trayectoria, así como de unos comportamientos que evocan deliberada y permanentemente al pasado. Se trata además de pautas peculiares y distintivas de Cogotas I, cuyas gentes desplegaron un amplio abanico de estrategias mnemónicas. Así, por una parte la transmisión de enlaces a corta distancia temporal pudo efectuarse por enculturación generacional, conformando tradiciones "genealógicas" (Gosden y Lock 1998: 5), ligadas a antepasados conocidos. Tal esquema convendría a la adopción de temas y patrones decorativos campaniformes (Fernández-Posse 1981; Fernández Moreno y Jimeno 1992). Por otro lado, de asumirse

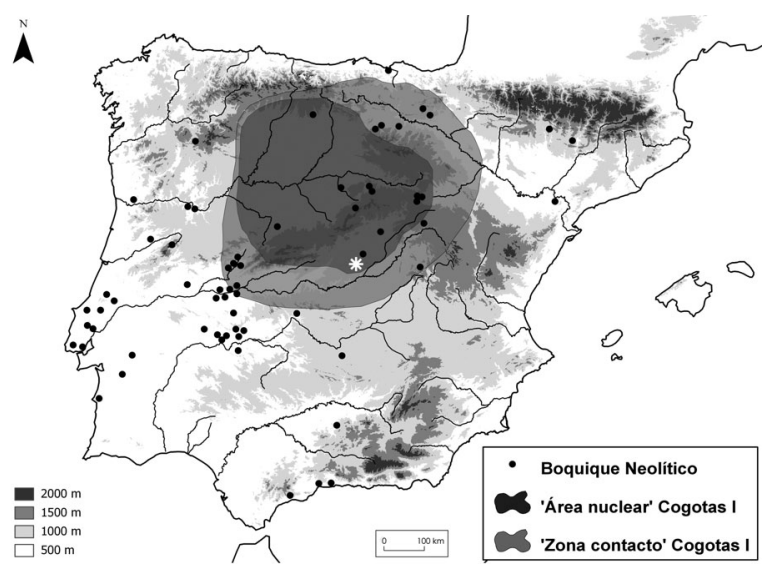

Fig. 3. Estaciones del Neolítico antiguo con Boquique y área nuclear / zona de contacto de Cogotas I en la Península Ibérica (a partir de Alday 2009: 24, mapa 1 y Abarquero 2005: 111, Fig. 20). El asterisco localiza la Fábrica de Ladrillos (Getafe, Madrid). 
la ruptura de la línea de transmisión de la alfarería incisa calcolítica (Blasco y Baena 1996: 433), su reaparición en el Bronce Medio podría entenderse por la confección de nuevos vínculos con el pasado. En el supuesto del nexo entre el Boquique neolítico y el cogotense estamos ante un claro hiato milenario, sólo sorteable mediante un reencuentro indirecto entre ambos, comportando "historias mitológicas", evocaciones más laxas del pasado (Gosden y Lock 1998: 6). Otros casos conocidos de inspiración en remotos motivos decorativos serían los de la cerámica "tipo Penha" calcolítica, "redescubierta" en el Bronce Final del noroeste peninsular (González Ruibal 2006/07: 112) o la alfarería neolítica escocesa, imitada en la Edad del Hierro (Hingley 1996: 240-241), tal vez para arraigar tales producciones y legitimar así la apropiación mítica del territorio.

Por todo lo dicho, concluiremos que la alfarería de Cogotas I podría definirse como una tradición inventada, que paulatinamente incorpora elementos selectos, procedentes de repertorios de otros contextos espacio-temporales. Al actuar así, los alfareros habrían partido del reconocimiento tanto de lo preexistente como de lo contemporáneo. El muestrario conseguido, con su marcado énfasis en remedar formas, temas y sintaxis asociados a las tradiciones autóctonas, parece responder al propósito explícito de subrayar deliberadamente ciertas afinidades con el pasado (Bradley 2002: 10-12). Tal planteamiento iluminaría la comprensión de la regionalización de la alfarería de Cogotas I en distintos subestilos o facies locales (Rodríguez Marcos 2008: 321-327), cuya variabilidad estilística parece tener correspondencia con las peculiaridades de las producciones locales calcolíticas y de comienzos de la Edad del Bronce (Samaniego et al. 2001: 99-100; Fabián 1995: 199-200).

Por encima de las particulares coyunturas a las que obedeciera cada innovación -algo siempre inusual y esporádico (Crown 2007; Budden y Sofaer 2009: 209)-, en conjunto la alfarería de Cogotas I responde a una tradición homogénea, en los términos planteados por Osborne (1998) y Hobsbawm (2002). Para Ruiz Zapatero (2007: 46): "esa sorprendente identidad sólo es explicable por la fuerza de la tradición de los alfareros y/o las alfareras y la significación visual de los códigos decorativos". Así pues, las sucesivas y excepcionales modificaciones del estilo alfarero de Cogotas I implicarían la manipulación cons- ciente y desigual de sus elementos formales. Las soluciones finalmente convenidas serían impuestas y sancionadas mediante formalidades, en contextos muy ritualizados, tal como veremos a continuación.

\subsubsection{El Boquique: técnica y ritualización}

Las consideraciones previas inciden en los aspectos más explícitos o conspicuos del estilo alfarero de Cogotas I, como referente identitario. Siguiendo a Wiessner (1983) se trataría de su dimensión "emblemática"; aquel patrón ideal y abstracto, normativo y consciente, orientado al exterior. Por contra, en los siguientes párrafos se insistirá en su vertiente tecnológica y en la rica información implícita, interiorizada como saber "no discursivo", de honda trascendencia social. Para ello debemos aproximarnos a la cultura material desde una racionalidad distinta a la nuestra. A la concepción partitiva y reduccionista de la técnica, como actividad instrumental de "especialistas", dirigida a resolver con eficacia necesidades funcionales, contraponemos una práctica social, probablemente a tiempo parcial, inserta en el marco inmanente de vivencias, significados y relaciones intersubjetivas en que se desenvolvieron los artesanos y artesanas (Ingold 1990: 10 y 14-15; Dobres 2000; Hendon 2010: 144-147). Por su parte, los productos pudieran comprenderse como objetos personales e inalienables, íntimamente vinculados a sus artífices, donde confluyen las relaciones sociales que rodearon su manufactura, uso y amortización (Thomas 1996; Chapman 2000b). Estos planteamientos se plasman a su vez en métodos de estudio que atienden a los procesos técnicos de la manufactura. Así, los saberes asimilados y las destrezas dominadas, las decisiones técnicas implicadas y las propias aptitudes artesanales son exhibidos como elementos socializadores, que informan de diversas "identidades técnicas" entre grupos de edad, sexo, pericia o experiencia (Gosselein 1998; Dietler y Herbich 1998; Dobres y Hoffman 1994).

Desde semejante perspectiva podemos acercarnos al estudio del Boquique (Fig. 4), como campo idóneo donde ensayarla, dotando de mayor contenido antropológico las apreciaciones tecnológicas ya planteadas por Maluquer de Motes (1956: 188-192) o Fernández-Posse (1982: 150). En los últimos años las aproximaciones al Boquique han replicado experimentalmente los 


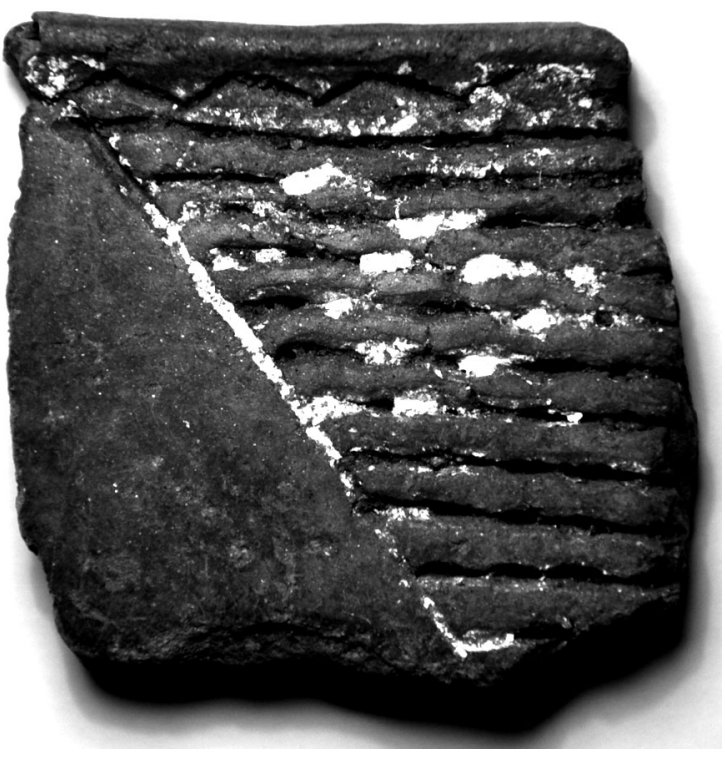

Fig. 4. Fragmento de borde de recipiente de Cogotas I decorado con Boquique y restos de pasta blanca. Cerro del Berrueco, Salamanca. Dimensiones: $3,8 \times 3,6 \mathrm{~cm}$. Foto: A. Blanco,

gestos técnicos involucrados (Mínguez 2005: 155-206; Alday 2009: 11-19). Los autores coinciden en señalar que tal técnica requirió un exigente aprendizaje, y una lenta y minuciosa ejecución (Alday 2009: 11-19), interviniendo conocimientos expertos y habilidades afianzadas, sólo transmisibles mediante aprendizaje tutelado (Crown 2007: 678-679). Tales caracteres no sólo le dotarían de un inestimable valor adicional (Abarquero 2005: 438), sino que permiten sospechar un contexto docente y socializador más complejo que el hasta ahora intuido. "La transmisión cerrada de las técnicas y motivos decorativos entre alfareros explica cómo el amplio elenco de esquemas decorativos se comparten en áreas muy extensas" (Ruiz Zapatero 2007: 46-47). Los escenarios de adoctrinamiento estuvieron muy probablemente cargados de connotaciones cosmogónicas y morales (Hendon 2010: 146-147), entre las cuales resaltamos aquí cierta vinculación consciente con el pasado mítico, aquel que hoy denominamos neolítico. Es decir, la alfarería de Cogotas I, lejos de responder a meras secuencias instrumentales, ejecutadas por individuos atendiendo a simples fines pragmáticos, utilitarios y asépticos, desacralizados y meramente estéticos, pudiera haber comportado pericias muy esmeradas, valoradas socialmente por su dificultad, por informar sobre la identidad y maestría del artesano y por su invocación del pasado.

La experimentación con el Boquique (Mínguez 2005: 197-201; Alday 2009: 11-20) relaciona la diversidad de resultados con factores como la materia prima, el instrumental empleado, la aptitud y experiencia del artesano o ciertas preferencias culturales contingentes, en gran parte compulsivas o "no discursivas" (Dobres 2000: 135; Dietler y Herbich 1998: 247). Sin embargo, tales muestras idiosincráticas y heterogéneas no excluyen un concepto ideal, un "efecto expresivo" o una "textura" concreta compartidos (Alday 2009: 18-19); en definitiva, un referente "emblemático" (Wiessner 1983). El Boquique comprende así fórmulas y soluciones procedimentales de resultados parecidos, que informan de la faceta "isocréstica" o equivalente (Sackett 1990: 33) de tal modalidad ornamental. Pero, como ya apuntara Fernández-Posse (1982: 150), su variabilidad "nada refleja en lo cultural o en lo cronológico": términos como "seudoBoquique" o "Boquique atípico" parten de un arquetipo estilístico arbitrario y convencional -el "típico", supuestamente más representativo- y no sirven como marcadores crono-culturales. Las secuencias artesanales informan sobre destrezas individuales, reproducen gestos compulsivos o inconscientes -los "hábitos-memoria" (10) - y responden a preferencias $\mathrm{y}$ decisiones sancionadas socialmente, que definen identidades tecnológicas compartidas (Dobres 2000: 164-211; Gamble 2001: 107-120; Lillios 2008: 76-117; Hendon 2010: 144-147). Todas esas manifestaciones "son" Boquique, cuya rica variabilidad debe ser estudiada. En concreto, resulta ineludible adoptar los métodos de la châine opératoire, para conectar tales habilidades y preferencias técnicas con los aspectos simbólicos e identitarios (Dietler y Herbich 1998; Gosselein 1998; Budden y Sofaer 2009).

Para superar la mera descripción formal debe obtenerse información tecnológica, priorizando la consecución de estudios arqueométricos, en especial de la composición química de las pastas, desgrasantes e inclusiones coloreadas, y de la temperatura de cocción. Los trabajos sobre incrustaciones de pasta blanca en cerámicas de Cogotas I permiten intuir el empleo de huesos triturados y calcinados (Odriozola 2007; Martín Gil y

(10) Postures and movements which are habit memories become sedimented into bodily conformation (Connerton 1989: 94). 
Martín Gil 2009). Tal elección técnica contrasta con la seguida entre los repertorios Ciempozuelos, basados mayoritariamente en el carbonato cálcico -rocas calcáreas o conchas de moluscos (Martín Valls y Delibes de Castro 1989: 5; Odriozola 2007: 135)- y sugiere interesantes cuestiones. Por otra parte, hay que preguntarse sobre la propia función del Boquique cogotense: ¿se hizo para ser visto, o para alojar pasta de color? Este asunto muy pocas veces se plantea, y pudiera ser crucial para comprender su intencionalidad. Si la pasta ocultaba siempre el modo de ejecutar los surcos, las clasificaciones estilísticas que manejamos serían irrelevantes a los ojos prehistóricos, y por tanto "las diferencias que se observan en la realización técnica no tendrían equivalente en los aspectos estilísticos" (Carmona Ballestero 2010: 52). Al respecto, se viene aceptando que el Boquique constituye una técnica "de incrustación", que remedaba el efecto de las cerámicas pintadas (Maluquer de Motes 1956: 188). A su vez, la muy desigual presencia de impregnaciones suele explicarse, tácitamente, por su azarosa conservación diferencial, debido a la erosión mecánica y química (Maluquer de Motes 1956: 190). A semejante imagen estática y definitiva de los recipientes cogotenses cabe hoy contraponer una cierta "biografía" o trayectoria de uso (Gamble 2001: 115-120; Crown 2007; Lillios 2008), que dotaría de connotaciones acumulativas a tales recipientes, conformando una suerte de "palimpsestos de significados" (Bailey 2007: 207-208). Según este último planteamiento, el Boquique consistiría en un dispositivo para incrustar pasta de color, si bien sólo algunas vasijas recibirían finalmente tales embadurnamientos. Además, no debemos descartar prácticas periódicas de lavados y "repintes" documentados etnográficamente en algunas alfarerías, creando así genealogías a través de tales "biografías" (Crown 2007: 680 y 686; Lillios 2008). La aplicación de pasta posterior a la cochura es técnicamente posible (Odriozola y Hurtado 2007) y, de hecho, algún ejemplar campaniforme francés (11) muestra una secuencia como la aquí sugerida, y que deberá buscarse. Así pues, atendiendo a la íntima asociación metonímica entre los objetos y las personas (Thomas

(11) Un examen de lámina delgada y otras técnicas de caracterización química, han permitido identificar la aplicación de dos capas de caolinita distintas, interpretada la segunda como una "restauración” (Covertini y Querré 1998: 339).
1996; Chapman 2000b; Brück 2006b), nos planteamos otras lecturas posibles. La pasta de color habría sido aplicada en concretos hitos biográficos -ritos de nacimiento, nupcias u óbito-, protagonizados por los sujetos a los que se asociarían tales recipientes y para los cuales pudieron incluso haberse confeccionado (Gallay 2007). Dichos eventos, muy ritualizados, de representación y exhibición ceremonial (Harrison 1995: 74; Abarquero 1997: 89; Budden y Sofaer 2009: 204-205), tan propios de las artesanías transformadoras de la materia, por su alto componente mágico (Brück 2006b: 306) resultarían idóneos para inculcar vínculos con la memoria colectiva (Connerton 1989; Dobres 2000; Bradley 2005: 29).

En suma; a través del Boquique se remitiría sutilmente a la memoria social, tanto entre los participantes en su elaboración mediante la adquisición de competencias técnicas (Dobres 2000; Lillios 2008; Budden y Sofaer 2009: 207-209), como entre su audiencia o usuarios, durante unas inopinadas trayectorias de uso y amortización de los recipientes. La refutación de tales planteamientos sobre el Boquique como elemento muy ritualizado, pasa por una buena caracterización tecnológica, desde un enfoque de la châine opératoire comprendida no como una forma de descripción, sino como una nueva estrategia metodológica de observación de los artefactos prehistóricos (Gosselain 2000; Dobres 2000; Li1lios 2008). Se despejarían así incógnitas sobre la identificación de probables servicios unitarios, tal vez elaborados por las mismas manos, o sobre la presencia de atributos "isocrésticos" similares, que reflejen identidades técnicas peculiares. Para reconocer los hipotéticos eventos biográficos y ceremoniales podrá cruzarse la información tecnológica con el estudio espacial de las pautas de fragmentación deliberada (Chapman 2000b: 49-104; Brück 2006a: 77-80) y la recomposición de recipientes incorporados a los hoyos (Garrow et al. 2005) en cuya caracterización volumétrica hay que insistir (Blasco Bosqued et al. 2007: 117-123), combinada con el estudio de los procesos tafonómicos del residuo (Schiffer 1987; Díaz-del-Río y Vicent 2006: 33).

\section{CONCLUSIONES}

En este texto se ha planteado la oportunidad de ensayar aproximaciones más inclusivas de la 
realidad social de Cogotas I, pertinentes y complementarias en el actual estado de la investigación. El avance en la caracterización de la subsistencia, el poblamiento y el medio ambiente debiera ser compatible con el estudio de las manifestaciones más cotidianas y contingentes, precisamente aquellas tratadas directamente por los arqueólogos, y que siguen constituyendo las fuentes primarias -con una mínima información contextual- para aproximarnos a la sociedad de Cogotas I. No se pretende reforzar el relativismo subjetivista, el idealismo conceptual y el énfasis en lo idiosincrásico y particular propio de la tradición disciplinar culturalista pues, ante todo, debe evitarse la deriva hacia una nueva simplificación. Se busca, en suma, aplicar las enseñanzas del "perspectivismo temporal" y aprehender las distintas manifestaciones de los fenómenos sociales atendiendo a metodologías y escalas acordes al registro disponible y al tipo de cuestiones planteadas (Bailey 2007: 201-202).

A lo largo del trabajo se han aportado argumentos para repensar críticamente nuestra comprensión de la esfera ritual y simbólica en Cogotas I. Lejos de considerarla accesoria o irrelevante, se ha pretendido mostrar su decisiva intervención para constituir y reproducir las relaciones sociales, como en la propia configuración del registro arqueológico. Pero su correcta apreciación pasa por un cambio de enfoque, que facilite la combinación de escalas y permita proceder desde los eventos particulares hacia las estructuras e instituciones. Desde tal perspectiva, encontramos recursos y estrategias que reflejan pautas de comportamiento muy estables, interiorizadas por los sujetos mediante socialización primaria, que constituyen $h a$ bitus: esquemas de predisposiciones para percibir, pensar y actuar de determinada forma (Bourdieu 1972: 178). Tales principios generativos presidirían de forma activa el aprendizaje, la percepción y las vivencias, y transformarían su contenido respondiendo al contexto social (Barrett 1994: 95; Chapman 2000b: 185), funcionando como "tecnologías de significado" que, a la larga, perpetuaron tales fórmulas culturales (Thomas 1996: 99-100). Al constreñir la capacidad de actuación de los agentes, pero al mismo tiempo, al habilitarles para actuar, habrían contribuido a constituir la sociedad de Cogotas I (Giddens 1995).

De momento, la falta de estudios ex profeso dota a nuestra propuesta de un evidente carácter provisional, pues apenas se sostiene con los datos disponibles. Pero, desde una posición cautelosa, pretendemos asentar las bases para afrontar con rigor tal línea de pesquisa. Sin los oportunos criterios "de alcance medio" (Chapman 2000b; Brück 2006b: 300) se nos objetará la dificultad de dilucidar entre el carácter deliberado o accidental de los comportamientos de cariz no utilitario. Sin embargo, incluso con las graves carencias indicadas, vamos perfilando ya ciertas regularidades: asociaciones y recurrencias de entidad suficiente para, al menos, cuestionarnos su presunto carácter esporádico y meramente azaroso. Sobre todo, hemos pretendido ampliar el campo de observación y redirigir la búsqueda de la esfera ritual.

Se ha sugerido el potencial interpretativo de dos elementos materiales que, por su amplia extensión y presencia cotidiana, resultan campos de estudio idóneos. En los hoyos, hemos rastreado la intervención de prácticas sociales distintivas, formalizadas y muy arraigadas, como el vertido pautado, la fragmentación intencionada o los depósitos especiales o codificados. La cerámica de Cogotas I cumple los requisitos para considerarse un caso de invención de una tradición cultural, sancionada por la emulación de técnicas y motivos ornamentales extintos -neolíticos, calcolíticos, campaniformes-. Semejante apropiación ideológica del pasado vendría favorecida por el contacto directo con los restos de tales artesanías caducas, con el propósito de vincular tales repertorios alfareros a los de los antepasados, implicando así cierta noción "histórica" sobre el paso del tiempo. Parte de la variabilidad cultural de Cogotas I responde por tanto a una inercia de largo alcance. De hecho, algunas preferencias idiosincrásicas de las pautas alfareras o fúnebres (Esparza 1990: 134) pueden rastrearse, retrospectivamente, en la propia diversidad de las tradiciones comarcales.

Concluimos que el registro material de Cogotas I responde a poderosas y duraderas motivaciones de orden social, profundamente arraigadas. En este sentido, hemos concedido gran importancia al concepto de "ritualización", que algunos autores (Hill 1995: 18-30 y 95; Bradley 2005: 207-209) consideran uno de los principales procesos implicados en la selección y formación del registro arqueológico, dotándolo de suficiente coherencia y regularidad como para ser interpretado hoy día. En el caso de Cogotas I, sus trazas físicas pueden ser en gran parte documentadas e interpretadas por responder a prácticas altamente 
formalizadas, con un especial acento en los procesos de amortización, abandono e "invisibilización" consciente y sistemática de ciertos contextos ordinarios y frecuentes (Fernández-Posse 1998: 242-243; Enríquez y Drake 2007: 164173). Los campos de hoyos responden a una casuística propia, ambivalente y muy ritualizada, distinta de la de aquellos espacios funcionalmente separados entre otras muchas culturas, con asentamientos, sitios cultuales y necrópolis segregados. Por contra, entre los grupos cogotenses otras conductas sociales fueron ritualizadas de otro modo -por ejemplo, las propias del ámbito doméstico e incluso la mayoría de las del funerario-, y han legado un rastro material mucho más fragmentario y menos perdurable. En consecuencia, hemos de reconsiderar la pretendida simplicidad y la aparente uniformidad del registro arqueológico de Cogotas I como una evidencia transparente, inocua y no problemática, cercana y familiar, de interpretación directa (Hill 1995: 4-5). Los testimonios reunidos vienen a contradecir el primer supuesto, mientras que recientes estudios (Díaz-del-Río y Vicent 2006) confirman la insólita variabilidad funcional de los campos de hoyos. Las principales diferencias vislumbradas entre la fase Protocogotas y los momentos avanzados de Cogotas I han de vincularse con cambios eminentemente simbólicos, plasmados en sus prácticas ritualizadas. Hasta mediados del II milenio AC se acentúan en especial ciertos depósitos -funerarios, de ofrendas animales o artefactos "singulares" como molinos barquiformes, recipientes invertidos, etc.-, asociados invariablemente a contextos de Protocogotas (Liesau et al. 2004/05; Liesau y Blasco 2006), como testimonia el depósito de fauna de los hoyos 76 y 78 de la Fábrica de Ladrillos, datado en el intervalo 1700-1520 cal AC (Blasco Bosqued et al. 2007: 50-58). Por contra, a partir de entonces, coincidiendo con Cogotas I Pleno, tales maneras desaparecen, mientras que la alfarería adquiere un énfasis ornamental inusitado (Fernández-Posse 1986; Ruiz Zapatero 2007), parejo a una mayor capacidad media en litros, tal como manifiestan los recipientes del fondo 12 del propio yacimiento madrileño mencionado, datado hacia 1140-900 cal AC (Blasco Bosqued et al. 2007: 121-122 y 193-194).

Nada puede afirmarse sobre los concretos y contingentes significados a los que sirvieron tales dispositivos sociales de invención / manteni- miento de la memoria social y las tradiciones culturales. Muy probablemente tales nociones y contenidos, polisémicos y dinámicos, hubieron de readaptarse, ante las cambiantes expectativas de las gentes de Cogotas I frente a situaciones sobrevenidas (Barrett 1994; Chapman 2000b). Tan sólo intuimos que la tenacidad de sus formas de expresión remite a cuestiones de suma importancia para las comunidades implicadas, lo que explicaría el cuidado puesto en su perpetuación. Por eso tal vez deban relacionarse con el aplacamiento de los riesgos e inseguridades consustanciales a los modos de vida de Cogotas I.

Estos planteamientos ayudarían a enfocar con nuevas lentes los peculiares rasgos de estos grupos prehistóricos, desde lecturas complementarias a las más usuales en la historiografía actual. Además de los intereses utilitarios, funcionales y sobre todo, relacionados con la subsistencia, comenzamos a intuir en el registro material de las gentes de Cogotas I otros propósitos relevantes. Son pautas que responden a hondos fundamentos sociales, plasmadas en comportamientos acordes con una racionalidad no instrumental, ni exclusivamente pragmática. En este trabajo se han recopilado argumentos para comenzar a esbozar semejante hipótesis. En lo sucesivo, las actuaciones arqueológicas sobre el registro de Cogotas I ofrecerán la oportunidad de contrastarla.

\section{AGRADECIMIENTOS}

Durante la elaboración del trabajo me he beneficiado de la discusión con Alfonso Alday Ruiz, Germán Delibes de Castro, Rafael Garrido Pena, Carlos Odriozola, Manuel Rojo Guerra y Gonzalo Ruiz Zapatero. Agradezco a la Dirección General de Patrimonio Cultural la cesión de los datos del Inventario Arqueológico de Castilla y León. El borrador inicial del texto recibió comentarios y aportaciones de Pedro Díaz-del-Río, Ángel Esparza, Alfredo González Ruibal, Elisa Guerra Doce, Alejandra Sánchez Polo, así como de dos evaluadores de la revista. A todos ellos les agradezco su esfuerzo.

\section{BIBLIOGRAFÍA}

Abarquero Moras, F. J. 1997: "El significado de la cerámica decorada de Cogotas I". Boletín del 
Seminario de Estudios de Arte y Arqueología LXIII: 71-96.

Abarquero Moras, F. J. 2005: Cogotas I. La difusión de un tipo cerámico durante la Edad del Bronce. Arqueología en Castilla y León 4, Monografías. Junta de Castilla y León. Valladolid.

Abarquero Moras, F. J. y Delibes de Castro, G. 2009: "La posición cronológica del yacimiento prehistórico de 'El Pelambre': apreciaciones tipológicas y dataciones absolutas". En M. ${ }^{\mathrm{a}}$ L. González Fernández (coord.): 'El Pelambre'. Villaornate, León. El horizonte Cogotas I de la Edad del Bronce y el período tardoantiguo en el valle medio del Esla. Tragsa. Madrid: 197-213.

Alday Ruiz, A. (ed.) 2009: Reflejos del Neolítico Ibérico. La cerámica Boquique: caracteres, cronología y contexto. Edar. Milán.

Alday Ruiz, A.; García Gazólaz, J. y Sesma Sesma, J. 2008: "La cerámica Boquique en contextos neolíticos peninsulares". En M. S. Hernández, J.A. Soler y J. A. López Padilla (eds.): Actas IV Congreso del Neolítico Peninsular (Alicante, 2006) 2: 157-166. Alicante.

Arnáiz Alonso, M. A. y Montero Gutiérrez, J. (2003/04): "El yacimiento de Cogotas I 'Tres Chopos-Abarre' (Villegas, Burgos): esbozo paleo-económico e implicaciones en las formas de organización social". Boletín del Seminario de Estudios de Arte y Arqueología LXIX-LXX: 75-114.

Bailey, G. 2007: "Time perspectives, palimpsests and the archaeology of time". Journal of Anthropological Archaeology 26: 198-223.

Barrett, J. C. 1994: Fragments from Antiquity: an Archaeology of Social Life in Britain 2900-1200 $A C$. Blackwell. Oxford.

Beguiristán Gúrpide, M. ${ }^{\mathrm{a}}$ A. y Vélaz Ciaurriz, D. 1999: "Megalitos, paisaje y memoria. Un estado de la cuestión". Memoria y Civilización 2: 317-327.

Bell, C. 1992: Ritual Theory, Ritual Practice. Oxford University Press. Oxford.

Bellido Blanco, A. 1996: Los campos de hoyos. Inicio de la economía agrícola en la Submeseta Norte. Studia Archaeologica 85, Universidad de Valladolid. Valladolid.

Berggren, A. 2009: "The relevance of stratigraphy". Archaeological Dialogues 16 (1): 22-25.

Blanco García, J. F. 2006: El Primer Milenio A.C. en la zona noroccidental de la provincia de Segovia: hacia la formación de Cauca (Coca) (siglos XI-V a.C.). Universidad Autónoma de Madrid. Madrid.

Blasco Bosqued, M. ${ }^{a}$ C. 2004: "Hacia una definición del Horizonte Cogotas I: algo más que un estilo cerámico". En L. Hernández y M. S. Hernández (eds.): La Edad del Bronce en tierras valencianas y zonas limitrofes. Instituto de Cultura Juan Gil-Albert. Alicante: 564-584.
Blasco, M. ${ }^{a}$ C.; Blanco, J.F.; Liesau, C.; Carrión, E.; García, J.; Baena, J.; Quero, S. y Rodríguez de la Esperanza, M. ${ }^{\mathrm{a}}$ J. 2007: El Bronce Medio y Final en la región de Madrid. El poblado de la Fábrica de Ladrillos (Getafe, Madrid). Estudios de Prehistoria y Arqueología Madrileñas 14-15.

Blasco Bosqued, M. ${ }^{\text {a }}$ C. y Lucas Pellicer, M. ${ }^{a}$ R. 2001: "Problemática del Bronce Final en la Meseta". Spal 10: 221-233.

Blasco, M. ${ }^{\text {a } ~ C . ; ~ S a ́ n c h e z-C a p i l l a, ~ M . ~}{ }^{a}$ L.; Calle, J.; Robles, F. J.; González, V. M. y González, A. 1991: "Enterramientos del horizonte Protocogotas en el valle del Manzanares". Cuadernos de Prehistoria y Arqueología de la Universidad Autónoma de Madrid 18: 55-112.

Bourdieu, P. 1972: Esquisse d'une théorie de la pratique. Droz. Genève. Paris.

Bradley, R. 2002: The past in prehistoric societies. Routledge. London.

Bradley, R. 2005: Ritual and domestic life in prehistoric Europe. Routledge. London.

Bradley, R. y Williams, H. (eds.): "The past in the past: the reuse of ancient monuments". World Archaeology 30 (1).

Brück, J. 1999: "Ritual and rationality. Some problems of interpretation in European archaeology". European Journal of Archaeology 2 (3): 313-344.

Brück, J. 2006a: "Death, exchange and reproduction in the British Bronze Age". European Journal of Archaeology 9 (1): 73-101.

Brück, J. 2006b: "Fragmentation, Personhood and the Social Construction of Technology in Middle and Late Bronze Age Britain". Cambridge Archaeological Journal 16 (3): 297-315.

Budden, S. y Sofaer, J. 2009: "Non-discursive Knowledge and the Construction of Identity Potters, Potting and Performance at the Bronze Age Tell of Százhalombatta, Hungary". Cambridge Archaeological Journal 19 (2): 203-220.

Carmona Ballestero, E. 2010: Prestigio y emulación en espacios marginales: la cerámica campaniforme de Paulejas (Quintanilla del Agua, Burgos). Estudios y monografías 50, Universidad de Burgos. Burgos.

Castro Martínez, P. V.; Micó, R. y Sanahuja, M. ${ }^{a}$ E. 1995: "Genealogía y cronología de la Cultura Cogotas I (El estilo cerámico y el grupo de Cogotas I en su contexto arqueológico)". Boletín del Seminario de Estudios de Arte y Arqueología LXI: 51-118.

Celis Sánchez, J.; Delibes de Castro, G.; Fernández Manzano, J.; Grau, L.; Hernández, M.; Herrán, J. I. y Rovira, S. 2007: "Consideración final: el depósito de Valdevimbre y la sociedad Cogotas I". En J. Celis, G. Delibes de Castro, J. Fernández Manzano y L. Grau (eds.): El hallazgo leonés de Valdevimbre y los depósitos del Bronce Final Atlántico 
en la Península Ibérica. Junta de Castilla y León y Diputación de León. León: 168-175.

Connerton, P. 1989: How societies remember. Cambridge University Press. Cambridge.

Connerton, P. 2009: How modernity forgets. Cambridge University Press. Cambridge.

Covertini, F. y Querré, G. 1998: “Apports des études céramologiques en laboratoire á la connaissance du Campaniforme: résultat, bilans et perspectives". Bulletin de la Société Préhistorique Française 95: 333-341.

Crown, P. L. 2007: "Life histories of pots and potters: situating the individual in archaeology". American Antiquity 72 (4): 677-690.

Cruz Sánchez, P. J. 2006/07: "La organización socio-económica de la Mesa de Carpio y su entorno (Villagonzalo de Tormes, Salamanca) a través de los artefactos macrolíticos pulimentados". Boletín del Seminario de Estudios de Arte y Arqueología LXXII- LXXIII: 93-121.

Chapman, J. 2000a: "Pit-digging and Structured Deposition in the Neolithic and Copper Age of Central and Eastern Europe". Proceedings of the Prehistoric Society 66: 61-87.

Chapman, J. 2000b: Fragmentation in Archaeology: People, Places and Broken Objects in the Prehistory of South-Eastern Europe. Routledge. London.

Delibes de Castro de Castro, G. 2000/01: "Del Bronce al Hierro en el valle medio del Duero: una valoración del límite Cogotas I-Soto de Medinilla a partir de las manifestaciones de culto". Zephyrus LIII-LIV: 293-309.

Delibes de Castro, G. 2004: "La impronta Cogotas I en los dólmenes del occidente de la cuenca del Duero o el mensaje megalítico renovado". Mainake 26: 211-231.

Delibes de Castro de Castro, G.; Romero Carnicero, F. y Abarquero Moras, F. J. 2000: “Cerámicas excisas de discutible filiación Cogotas I en el Bronce Tardío de la Península Ibérica: una taza de estilo 'Duffaits' procedente de la Cueva del Asno (Los Rábanos, Soria)". En E. Baquedano (coord.): Soria Arqueológica. A José Luis Argente Oliver. Diputación de Soria. Soria: 97-130.

Díaz-del-Río, P. 2001: La Formación del Paisaje Agrario: Madrid en el III y II milenios AC. Comunidad de Madrid. Madrid.

Díaz-del-Río, P. y Vicent, J. 2006: “Movilidad, funcionalidad y usos del suelo en la Prehistoria Reciente". En A. Orejas (coord.): Espacios Agrarios. Arqueología Espacial 26: 21-36.

Dietler, M. y Herbich, I. 1998: "Habitus, techniques, style: an integrated approach to the social understanding of material culture and boundaries". En M. T. Stark (ed.): The Archaeology of Social Boundaries. Smithsonian Institution Press. Washington D.C.: 232-263.
Dobres, M.-A. 2000: Technology and social agency. Outlining a practice framework for Archaeology. Blackwell. Oxford.

Dobres, M.-A. y Hoffmann, C. R. 1994: "Social agency and the dynamics of prehistoric technology". Journal of Archaeological Method and Theory 1(3): 211-258.

Dobres, M.-A. y Robb, J. (eds.): 2000: Agency in Archaeology. Routledge. London.

Enríquez Navascués, J. J. y Drake García, B. 2007: El Campo de Hoyos de la Edad del Bronce del Carrascalejo (Badajoz). Junta de Extremadura. Mérida.

Esparza Arroyo, A. 1990: "Sobre el ritual funerario de Cogotas I". Boletín del Seminario de Estudios de Arte y Arqueología LVI: 105-143.

Esparza Arroyo, A. 2001: "Pre-historical Prehistory? A reply to Martin Kuna". Prehistoria 2000 I (1): 115-137.

Esparza Arroyo, A. 2009: "Recuperando el tiempo perdido". Trabajos de Prehistoria 66 (1): 185-187.

Esparza, A.; Delibes de Castro, G.; Ramos, P. y Salvador, M. 2008: "Una nueva sepultura del grupo Cogotas I en 'El Juncal' (Villaralbo, Zamora)". Zephyrus LX (1): 155-175.

Fabián García, J. F. 1995: El aspecto funerario durante el Calcolítico y los inicios de la Edad del Bronce en la Meseta Norte. Estudios Históricos y Geográficos 93, Universidad de Salamanca. Salamanca.

Fernández Moreno, J. J. y Jimeno Martínez, A. 1992: "Los Arenales de Rioseco (Soria): consideraciones sobre la relación de cerámicas campaniformes y Cogotas I". 2. 'Symposium de Arqueología Soriana (Soria, 1989): 211-229. Soria.

Fernández-Posse, M. ${ }^{a}$ D. 1981: "La cueva de Arevalillo de Cega (Segovia)". Noticiario Arqueológico Hispanico 12: 43-84.

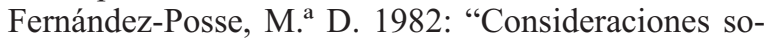
bre la técnica del Boquique”. Trabajos de Prehistoria 39: 137-159.

Fernández-Posse, M. a D. 1986/87: "La cerámica decorada de Cogotas I'. Zephyrus XXXIX-XL: 231-237.

Fernández-Posse, M. ${ }^{a}$ D. 1998: La investigación protohistórica en la Meseta y Galicia. Síntesis. Madrid.

Gallay, A. 2007: "Les jarres de mariage décorées du delta intérieur du Niger (Mali): Essai de délimitation archéologique". The Arkeotek Journal 1 (1), http://www.thearkeotekjournal.org (consulta febrero 2010$)$.

Gamble, C. 2001: Archaeology: The Basics. Routledge. London.

García Sanjuán, L. 2005: "Las piedras de la memoria. La permanencia del megalitismo en el Suroeste de la Península Ibérica durante el II y I milenios ANE". Trabajos de Prehistoria 62 (1): 85-109. 
Garrido Pena, R. 2000: El Campaniforme en la Meseta Central de la Península Ibérica (c. 2500-2000 A.C.). British Archaeological Reports, International Series 892. Archaeopress. Oxford.

Garrow, D.; Beadsmoore, E. y Knight, M. 2005: "Pit clusters and the Temporality of Occupation: an Earlier Neolithic Site at Kilverstone, Thetford, Norfolk". Proceedings of the Prehistoric Society 71: 139-157.

Giddens, A. 1995: La constitución de la sociedad: bases para la teoría de la estructuración. Amorrortu. Buenos Aires.

González Fernández, M. ${ }^{a}$ L. (coord.) 2009: 'El Pelambre' Villaornate, León. El horizonte Cogotas I de la Edad del Bronce y el período tardoantiguo en el valle medio del Esla. Tragsa. Madrid.

González Ruibal, A. 2006/07: Galaicos. Poder y comunidad en el Noroeste de la Península Ibérica (1200 a.C.-50 d.C.). Brigantium 18. Museo de San Antón. A Coruña.

González-Tablas, F. J. y Fano Martínez, M. A. 1994: "El fenómeno de la muerte en Cogotas I: una propuesta metodológica". Zephyrus XLVII: 93-103.

Gosden, C. y Lock, G. 1998: "Prehistoric histories". En R. Bradley y H. Williams (eds.): The past in the past: the reuse of ancient monuments. World Archaeology 30 (1): 2-12.

Gosselein, O. P. 1998: "Social and technical identity in a clay crystal ball". En M. T. Stark (ed.): The Archaeology of Social Boundaries. Smithsomian Institution Press. Washington: 78-106.

Gosselein, O. P. 2000: "Materializing identities: An African perspective". Journal of Archaeological Method and Theory 7 (3): 187-217.

Harding, A. 2006: "Pit-Digging, Occupation and Structured Deposition on Rudston Wold, Eastern Yorkshire". Oxford Journal of Archaeology 25 (2): 109-126.

Harrison, R. J. 1995: "Bronze Age expansion 17501250 AC: The Cogotas I Phase in the Middle Ebro Valley". Veleia 12: 67-77.

Hendon, J. A. 2010: Houses in a Landscape. Memory and Everyday Life in Mesoamerica. Duke University Press. Durham.

Hernando Gonzalo, A. 2002: Arqueología de la Identidad. Akal. Madrid.

Hill, J. D. 1995: Ritual and rubbish in the Iron Age of Wessex. A study on the formation of a specific archaeological record. British Archaeological Reports, British Series 242, Archaeopress. Oxford.

Hingley, R. 1996: "Ancestors and identity in the later prehistory of Atlantic Scotland: the reuse and reinvention of Neolithic monuments and material culture". World Archaeology 28 (2): 231-243.

Hobsbawm, E. R. 2002: "Introducción. La invención de la tradición". En E. R. Hobsbawm y T. Ranger (eds.): La invención de la tradición. Crítica. Barcelona: 7-21.

Hodder, I. y Cessford, C. 2004: "Daily practice and social memory at Çatalhöyük". American Antiquity 69 (1): 17-40.

Hodder, I. y Hutson, S. 2003: Reading the past. Current approaches to interpretation in Archaeology. Cambridge University Press. Cambridge.

Ingold, T. 1990: "Society, nature and the concept of technology". Archaeological Review from Cambridge 9 (1): 4-17.

Jiménez Jáimez, V. y Márquez Romero, J. E. 2008: “"Aquí no hay quien viva'. Sobre las casas-pozo en la Prehistoria de Andalucía durante el IV y el III milenios AC". Spal. Revista de Prehistoria y Arqueología 15: 39-50.

Jimeno, A. 1988: "La investigación del Bronce Antiguo en la Meseta Superior". Trabajos de Prehistoria 45: 103-121.

Jones, A. 2007: Memory and Material Culture. Cambridge University Press. Cambridge.

Kuna, M. 1995: "Pre-historic prehistory". En M. Kuna y N. Venclová (eds.): Writer Archaeology? Papers in Honour of Evzen Neustupny. Institute of Archaeology, Academy of Sciences of the Czech Republic. Praha: 43-51.

Liesau, C.; García, J.; Carrión, E. y Blasco, M. ${ }^{a}$ C. 2004/05: "El depósito ritual del fondo 76-78 de la Fábrica de Ladrillos (Getafe, Madrid)". Cuadernos de Prehistoria y Arqueología de la Universidad Autónoma de Madrid 30-31: 47-56.

Liesau, C y Blasco, M. ${ }^{a}$ C. 2006: "Depósitos con fauna en yacimientos del Bronce Medio en la Cuenca del Tajo". En N. Ferreira Bicho (ed.): Animais na Pré-história e Arqueología da Península Ibérica. Actas do IV Congresso de Arqueología Peninsular (Faro, 2004): 81-92. Braga.

Lillios, K. T. 2008: Heraldry for the Dead. Memory, Identity and the Engraved Stone Plaques of Neolithic Iberia. University of Texas Press. Austin.

López Sáez, J. A. y Blanco González, A. 2004: “El paisaje de una comunidad agraria en el borde de la Cuenca del Duero: análisis paleopalinológico del yacimiento Protocogotas de la Gravera de Puente Viejo (Mingorría, Ávila, España)". Zephyrus LVII: 195-219.

Lorrio Alvarado, A. J. y Montero Ruiz, I. 2004: "Reutilización de sepulcros colectivos en el Sureste de la Península Ibérica: la Colección Siret". Trabajos de Prehistoria 61 (1): 99-116.

Maluquer de Motes, J. 1956: "La técnica de incrustación del Boquique y la dualidad de tradiciones técnicas en la Meseta durante la Edad del Hierro". Zephyrus VII: 179-206.

Márquez Romero, J. E. 2002: "De los campos de silos a los agujeros negros: sobre pozos, depósitos y zanjas en la Prehistoria Reciente del Sur de la Penínsu- 
la Ibérica". Spal. Revista de Prehistoria y Arqueología 10. Homenaje al Profesor Pellicer (I): 207-220.

Márquez Romero, J. E. 2004: "Muerte ubicua: sobre deposiciones de esqueletos humanos en zanjas y pozos en la Prehistoria Reciente de Andalucía”. Mainake 26: 115-138.

Martín-Gil, J. y Martín-Gil, F. J. 2009: “Caracterización de una pasta blanca de relleno en las decoraciones cerámicas de la Edad del Bronce de El Pelambre". En M. ${ }^{\mathrm{a}}$ L. González Fernández (coord.): 'El Pelambre' Villaornate, León. El horizonte Cogotas I de la Edad del Bronce y el período tardoantiguo en el valle medio del Esla. Tragsa. Madrid: 191-195.

Martín Valls, R. y Delibes de Castro de Castro, G. 1989: La cultura del vaso campaniforme en las campiñas meridionales del Duero. El enterramiento de Fuente-Olmedo (Valladolid). Monografías del Museo Arqueológico de Valladolid 1. Valladolid.

Martínez Navarrete, M. ${ }^{a}$ I. 1988: La Edad del Bronce en la Submeseta Suroriental: una revisión crítica. Colección Tesis Doctorales, 191/88, Universidad Complutense de Madrid. Madrid.

Mataloto, R. 2007: "Paisagem, memória e identidade: tumulações megalíticas no pós-megalitismo alto-alentejano". Revista Portuguesa de Arqueologia 10 (1): 123-140.

Maya, J. L. y Petit, M. ' A. 1986: "El grupo del nordeste. Un nuevo conjunto de cerámicas con Boquique en la península Ibérica". Anales de Prehistoria y Arqueología 2: 48-71.

McAnany, P. A. y Hodder, I. 2009: “Thinking about stratigraphic sequence in social terms". Archaeological Dialogues 16 (1): 1-22.

Mills, B. J. 2009: "From the ground up. Depositional history, memory and materiality". Archaeological Dialogues 16 (1): 38-40.

Mínguez Álvaro, M. ${ }^{\text {a }}$ T. 2005: Estudios sobre Atapuerca (Burgos). III, Los materiales del Bronce Final de 'El Portalón' de Cueva Mayor. Universidad de Deusto. Bilbao.

Molina, F. y Arteaga, O. 1976: "Problemática y diferenciación en grupos de la cerámica con decoración excisa en la Península Ibérica". Cuadernos de Prehistoria de la Universidad de Granada 1: 175-214.

Norman, N. 2009: "Powerful Pots, Humbling Holes, and Regional Ritual Processes: Towards an Archaeology of Huedan Vodun, ca. 1650-1727'. African Archaeological Review 26 (3): 187-218.

Odriozola, C. P. 2007: “Caracterización cerámica del Carrascalejo”. En J. J. Enríquez Navascués y B. Drake García (eds.): El Campo de Hoyos de la Edad del Bronce del Carrascalejo (Badajoz). Junta de Extremadura. Mérida: 133-144.

Odriozola, C. P. y Hurtado Pérez, V. M. 2007: “The manufacturing process of $3 \mathrm{rd}$ millennium $\mathrm{AC}$ bone based incrusted pottery decoration from the Middle Guadiana river basin (Badajoz, Spain)". Journal of Archaeological Science 34 (11): 1794-1803.

Osborne, R. 2008: "Introduction: for tradition as an analytical category". World Archaeology 40 (3): 281-294.

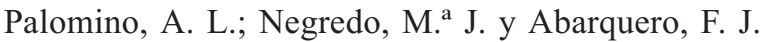
1999: "Cabañas, basureros, silos y tumbas en el yacimiento de El Cerro, La Horra (Burgos). A vueltas sobre el significado de un campo de hoyos en la Edad del Bronce de la Meseta". Numantia 7: 21-41.

Pollard, J. 2001: "The aesthetics of depositional practice". World Archaeology 33 (2): 315-333.

Rojo Guerra, M. A.; Kunst, M.; Garrido Pena, R.; García Martínez-de-Lagrán, I. y Morán Dauchez, G. 2008: Paisajes de la memoria: asentamientos del Neolítico antiguo en el Valle de Ambrona (Soria, España). Instituto Arqueológico Alemán y Universidad de Valladolid. Valladolid.

Richards, C. y Thomas, J. 1984: "Ritual activity and structured deposition in Later Neolithic Wessex". En R. Bradley y J. Gardiner (eds.): Neolithic studies. A review of some current research. British Archaeological Reports, British series 133, Archaeopress. Oxford: 189-218.

Rodríguez Marcos, J. A. 2008: Estudio secuencial de la Edad del Bronce en la Ribera del Duero (provincia de Valladolid). Junta de Castilla y León. Valladolid.

Rodríguez Marcos, J. A. y Abarquero, J. 1994: “Intervención arqueológica en el yacimiento de la Edad del Bronce de 'El Cementerio-El Prado' (Quintanilla de Onésimo) Valladolid”. Numantia 5: 33-57.

Rowlands, M. 1993: "The role of memory in the transmission of culture". World Archaeology 25: 141-151.

Ruiz Zapatero, G. 2007: “Antes del Hierro. Cultura y sociedad en el centro de la Meseta (ca. 1200-500 a.C.)". En A. F. Dávila (ed.): Estudios sobre la Edad del Hierro en la Carpetania. Registro arqueológico, secuencia y territorio. Zona Arqueológica 10, I: 36-63.

Samaniego, B.; Jimeno, A.; Fernández Moreno, J. J. y Gómez Barrera, J. A. 2001: Cueva Maja (Cabrejas del Pinar. Soria): Espacio y simbolismo en los inicios de la Edad del Bronce. Arqueología en Castilla y León 10. Memorias. Junta de Castilla y León. Valladolid.

Sackett, J. R. (1990): "Style and ethnicity in Archaeology: the case for isochrestism". En M. W. Conkey y C. A. Hastorf (eds.): The Uses of Style in Archaeology. Cambridge University Press. Cambridge: 32-43.

Schiffer, M. B. 1987: Formation processes of the Archaeological Record. Alburquerque. 
Shanks, M. y Tilley, C. 1987: Social Theory and Archaeology. Routledge. London.

Thomas, J. 1996: Time, Culture and Identity. An Interpretive Archaelogy. Routledge. London.

Thomas, J. 1999: Understanding the Neolithic. Routledge. London.

Valiente Malla, J. 1993: "Un rito de fertilidad agraria de la Edad del Bronce en la Loma del Lomo
(Cogolludo, Guadalajara)". En Homenaje a José María Blázquez I. Ediciones Clásicas. Madrid: 253-265.

Van Dyke, R. M. y Alcock, S. (eds.) 2003: Archaeologies of Memory. Blackwell. Oxford.

Wiessner, P. 1983: "Style and social information in Kalahari San projectile points". American Antiquity 48: 253-276. 